Savunma Bilimleri Dergisi

The Journal of Defense Sciences

Kasim / Nov 2019, Cilt/Volume 18, Say1/Issue 2.

ISSN (Bas111) : 1303-6831 ISSN (Online): 2148-1776

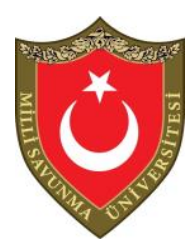

\title{
Stokastik Talepli Araç Rotalama Problemi İçin Literatür Taraması
}

\author{
Beste DESTİCIOĞLU* ve Bahar ÖZYÖRÜK ${ }^{* *}$ \\ $\ddot{O} z$
}

Araç Rotalama Problemi (ARP), bir işletmenin farklı konumlarda yer alan müssterilerine bir veya birden fazla depodan, tek veya çok araçla hizmet verebilmek için maliyeti minimize edecek şekilde uygun rotaların belirlenmesi problemidir. Ancak gerçek hayat problemlerinde bütün parametrelerin önceden bilindiği deterministik problemlerden çok, olasıllklı bilgilerin yer aldiğı Stokastik Araç Rotalama Problemi (SARP) ile karşılaşılmaktadır. Literatürde SARP konusunda yapılan çalışmalar incelendiğinde, araştırmacıların en çok stokastik talebin yer aldı̆̆ stokastik talepli araç rotalama problemini (STARP) inceledikleri tespit edilmiştir. Bu çalı̧̧mada da müşteri taleplerinin araç müşteri lokasyonuna gidene kadar kesin olarak bilinmediği, ancak müşteri lokasyonuna varıldı̆̆ında öğrenildiği durum incelenmiştir. STARP'da müşterilerden gelen taleplerin belirli bir olasılık dăğlımına sahip rassal değişkenlerden oluştuğu kabul edilmektedir. STARP konusunda literatürde yapılan çalışmalar ayrıntılı olarak incelenmiş ve belirlenen kısıtlar altında bir sınıflandırma yapılmıştır. STARP konusunda yapılan çalı̧̧malar bu sinıflandırmaya göre değerlendirilmiş, STARP için geliştirilen matematiksel modeller ile problemin çözümü için önerilen çözüm yaklaşımları hakkında bilgi verilmiş ve araştırmacıların en çok hangi problem üzerinde yoğunlaştıkları belirlenmeye çalışılmıştır.

Anahtar Kelimeler: Araç Rotalama Problemi, Stokastik Talepli Araç Rotalama Problemi, Yardımcı Eylemli Stokastik Programlama, Şans Kısıtlı Stokastik Programlama.

\footnotetext{
* Araştırma Görevlisi, Milli Savunma Üniversitesi, Alparslan Savunma Bilimleri Enstitüsü, Harekât Araştırması Ana Bilim Dalı, bdesticioglu@kho.edu.tr

** Doktor Öğretim Üyesi, Gazi Üniversitesi Endüstri Mühendisliği Bölümü, bahar@gazi.edu.tr

Geliş Tarihi/Received : 16.09.2019

Kabul Tarihi/Accepted : 16.10.2019

Araştırma Makalesi/Research Article
} 


\title{
Literature Review for Vehicle Routing Problem with Stochastic Demands
}

\begin{abstract}
Vehicle Routing Problem (VRP) is the problem of identifying suitable routes in a way that minimizes the cost in order to serve customers in different locations from one or more depots by one or more vehicles. However, in real life problems, Stochastic Vehicle Routing Problem (SVRP) with stochastic information appears more than deterministic problems in which all parameters are known in advance. When the studies on SVRP in the literature are examined, it is found that the researchers study the most about vehicle routing problem with stochastic demand (VRPSD) in which stochastic demand takes place. In this study, a situation was examined in such a way that customer demands are not known exactly until the vehicle reaches the customer location. In VRPSD, it is accepted that the demands from customers consist of random variables with a certain probability distribution. Studies on VRPSD in the literature have been examined in detail and a classification has been made under the specified constraints. Studies on VRPSD are evaluated according to this classification, mathematical models developed for VRPSD and the proposed solution approaches for solving the problem are laid out and an effort is made to determine which problem the researchers concentrated on the most.
\end{abstract}

Keywords: Vehicle Routing Problem, Vehicle Routing Problem with Stochastic Demand, Stochastic Programming with Recourse, Chance Constrained Stochastic Programming.

\section{Giriş}

Farklı noktalarda yer alan müşterilerin taleplerinin, bir veya birden fazla depodan, tek veya çok araçla karşılanması problemi literatürde Araç Rotalama Problemi (ARP) olarak bilinmektedir. ARP'da amaç, belirlenen kısıtlara uyularak minimum maliyetle en uygun rotaların oluşturulmasıdır. Bu problem literatüre ilk kez Dantzig ve Ramser tarafından kazandırılmıştır. Günümüzde de araştırmacılar, ARP'a yeni kısıtlar ekleyerek, problemi gerçek hayatta karş1laş1labilecek 
durumlar için uyarlamaktadır. ARP konusunda yapılan çalışmalar incelendiğinde, bu problemin dinamik-statik, tek araçl1-çok araçlı, tek depolu-çok depolu, zaman pencereli- zaman kısıtlı, sadece dağıt, topla-dağıt veya eş zamanlı topla dağıt gibi çeşitli kısıtlar altında çalışıldığı görülmektedir. Literatürdeki çalışmalara bakıldığında, farklı kısıtları içeren ARP'lerin birçok araştırmacı tarafından incelendiği dikkat çekmektedir. Literatürde en çok çalış1lan ARP, birden fazla deponun yer aldığ Çok Depolu ARP (ÇDARP) ve aynı zamanda müşterilerin toplama ve dağıtım taleplerinin gerçekleştirildiği Eş Zamanlı Topla Dağıt ARP (ETD_ARP)'dir. Günümüzde gerçek hayat problemleri için daha uygun olan, değişken bilgiler içeren, Dinamik ARP (DARP) ve Stokastik ARP (SARP), araştırmacılar için ilgi çekici konular haline gelmiştir. Son yıllarda araştırmacılar bu problem türlerinde birçok çalışma yapmıştır. Desticioğlu ve Özyörük (2019), Dinamik ARP, Eş Zamanlı Topla Dağıt ARP ve Çok Depolu ARP konusunda literatürde yapılan çalışmaları ele alan ayrıntılı bir literatür taraması yapmıştır.

SARP, deterministik ARP'da yer alan bir veya birden fazla parametrenin kesin olarak bilinmemesi durumunda ortaya çıkmaktadır. Stokastik bilgi içerebilecek değişkenler müşteriler, seyahat süresi, servis süresi veya müşteri talepleri olabilir. $\mathrm{Bu}$ parametreler olasılık dağılımları bilinen rassal değişkenlerden oluşmaktadır. (Ritzinger, Punchinger ve Hartl, 2015). Bu problemde de amaç, beklenen rotalama maliyetinin minimize edilmesidir. Ancak SARP'da rotalar belirlendikten sonra, stokastik bilgilerdeki değişiklik ile rotaların güncellenmesi gerekebilmektedir. Planlanan rota, başlangıçtaki taleplerden oluşturulan rotadır. Araç rotada devam ederken, bir müşterinin talebini gerçekleştirdikten sonra, ya sonraki müşteriye hareket eder ya da araca yeniden yükleme yapmak için depoya döner (Kızıloğlu, 2017).

SARP'nin, Stokastik Müşterili ARP, Stokastik Talepli ARP, Stokastik Servis Süreli ARP, Stokastik Seyahat Süreli ARP gibi çeşitleri bulunmaktadır. SARP konusundaki çalışmalar incelendiğinde, araştırmacıların en çok Stokastik Talepli Araç Rotalama Problemi (STARP) üzerine yoğunlaştığı tespit edilmiştir. STARP'nin özelliği, müşterilerden gelen taleplerin belirli bir olasılık dağglımına sahip rassal değişkenlerden oluşmasıdır (Kızıloğlu, 2017).

ARP, NP-hard sınıfında yer almaktadır ve günümüz şartlarında problem boyutunun giderek artması ve probleme yeni kısitlar eklenmesi problemin kesin yöntemlerle çözümünü daha da zorlaştırmaktadır. Deterministik hali bile makul sürede çözülemeyen bu problemin, daha karmaşık yapıda olan stokastik halinin 
de NP-hard özellikte olacağı açıktır. Bu yüzden literatürdeki çalışmalar incelendiğinde, ARP'1 ve SARP'1 makul sürede çözebilmek ve kaliteli çözümler elde edilebilmek için sezgisel ve metasezgisel yöntemler kullanıldığı görülmektedir (Kızıloğlu, 2017).

Bu çalışmada ilk olarak STARP hakkında genel bilgi verilmiş ve STARP konusunda yapılan çalışmalar için bir sınıflandırma yapılmıştır. $\mathrm{Bu}$ sınıflandırmalarda yer alan çalışmalar hakkında ayrıntılı bir analiz yapılmış ve STARP için geliştirilen matematiksel modeller ve problemlerin çözüm yöntemleri hakkında bilgi verilmiştir. Daha sonra belirlenen kısıtlar dikkate alınarak, araştırmacıların en çok hangi problem çeşidini çalıştı̆̆ belirlenmiştir. Sonuç bölümünde STARP konusundaki çalışmalar hakkında genel bir değerlendirme yapılmış ve gelecekte incelenebilecek problemler hakkında bilgi verilmiştir.

\section{Stokastik Talepli Araç Rotalama Problemi (STARP)}

STARP, müşteri taleplerinin kesin olarak bilinmediği ve talep miktarının ancak araç müşteriye lokasyonuna varıldığında kesin olarak öğrenildiği araç rotalama problemidir. Problemde, hizmet verilecek müşteri taleplerinin belirli bir olasılık dağılımından geldiği varsayılmaktadır (Gültepe, 2011).

STARP günlük hayatta birçok alanda karşımıza çıkmaktadır. Evlere yakıt dağıtımı, banka şubelerine nakit para dağıtımı / toplanması, atık suların arıtılması sırasında çamurun bertaraf edilmesi, çay-kahve ve bisküvi otomatlarının stok miktarının belirlenmesi, çöp toplama hizmetleri, büfelere/marketlere dağıtılan içecek miktarları, insani yardım lojistiği, benzin istasyonlarına yakıt ikmali vb. STARP'a örnek olarak verilebilir (İşleyen, 2008).

Gerçek hayat problemleri incelendiğinde, problemdeki parametrelerin her zaman deterministik olmadığı, çoğu durumda rassal değişkenlerden oluştuğu görülmektedir. Bu gibi durumlarda doğrusal progamlama yaklaşımı da problemin modellenmesi için kullanılamamaktadır. Bu yüzden rassal değişkenlerin yer aldığı problemler stokastik programlama yaklaşımıyla modellenmektedir (Kızıloğlu, 2017). STARP ile ilgili yapılan çalışmalar incelendiğinde, modellemede Şans Kısıtlı Programlama (Chance Constraint Stochacastic Programming, CCP) ve Yardımcı Eylemli Stokastik Programlama (Stochastic 
Programming with Recourse, SPR) yaklaşımlarının kullanıldığı görülmüştür (Oyola, Arntzen, Woodruff, 2018).

Şans kısıtı yaklaşımı, stokastik değişken içeren kısıtlar ve amaç fonksiyonun yer aldığı problemde, belirli bir olasılık dağılımına sahip olan değişkenlerin mümkün olduğu ölçüde deterministik hale getirilmesidir (Kızıloğlu, 2017). Şans kısıtlı stokastik programlamada, stokastik bilginin yer aldığ deterministik kısıtlar, stokastik kısıt kümesi ile değiştirilmektedir (Uslu, 2016).

Yardımc eylemli stokastik programlamada ise rota kırılmasına izin verilmektedir. Ancak, rota kırılması sonrasında, rotanın düzenlenebilmesi için karar vericinin hangi yardımcı eylem politikasının kullanması gerektiğini belirlemesi gerekmektedir. Yardımcı eylemli stokastik programlama modelinin çözümü, şans kısıtlı stokastik programlama modellerine göre daha zordur, ancak ele aldığı amaçlar model için daha çok önem taşımaktadır (Gendreau, Laporte, Guo, 1996). Yardımc1 eylemli stokastik programlamada yaygın olarak kullanılan 3 çeşit yardımcı eylem bulunmaktadır:

1. Araç kapasitesi aşıldığında veya müşteri talepleri karşılanamadığında, araç boşaltma veya yükleme işlemini gerçekleştirmek için depoya geri döner. Daha sonra araç rotasına, rota kırılmasının meydana geldiği müşteriden başlayarak devam eder. Bu yardımcı eylem politikası literatürde Depoya Geri Dönüş (detour-to-depot, DTD) olarak bilinmektedir.

2. Araç rota kırılmasına uğramadan önce depoya giderek, araca yükleme işlemini gerçekleştirebilir.

3. Aracın rotasında, rota kırılması meydana geldikten sonra veya müşteriye hizmet verildikten sonra, rota kalan hizmet verilmemiş müşterileri de içerecek şekilde yeniden optimize edilir. Hangi müşterinin daha sonra ziyaret edilmesiyle ilgili olarak verilen karar, düzenlenen rotanın belirli bir parçasıyla devam etme veya araca yeniden yükleme yapmak için depoya dönmesi şeklinde olabilir (Oyala vd, 2018).

Araştırmacılar STARP konusunda iki çeşit çalışma üzerinde yoğunlaşmışlardır. İlki, STARP için uygun matematiksel modelin oluşturulması ve bu modelin çözümüne ilişkin olarak yapılan çalışmalardır. Diğeri ise STARP'ın çözümüne ilişkin algoritmaların geliştirilmesine yönelik yapılan çalışmalardır. Algoritma çalışmalarında genellikle matematiksel model tanımlamasına yer verilmediği tespit edilmiştir. Problemin çözümü için ise 
genellikle sezgisel ve metasezgisel yöntemlerin kullanıldığ görülmektedir (Oyola vd., 2018).

$\mathrm{Bu}$ bölümde literatürde STARP konusunda yapılan çalışmalar ayrıntılı olarak değerlendirilmiş, literatürde en çok karşılaşılan kısıtları içeren STARP çeşitleri ayrı başlıklar altında ele alınmıştır.

\section{Çok Araçı STARP Hakkında Yapılan Çalışmalar}

STARP konusunda literatürde birçok çalışma yapılmıştır. Bu çalışmalara bakıldığında, en çok Çok Araçlı STARP'ın araştırmacılar tarafından incelendiği görülmektedir. Zaten ARP, genelde birden fazla aracın rotalarının tasarlandığ problemdir. Özel olarak belirtilmediği sürece problemde çok araçlı durum incelenmektedir. Bu yüzden bu çalışmada da çok araçlı problem için kısaca STARP denilmiştir. Bu bölümde çok araçlı STARP konusunda yapılan çalışmalar incelenmiştir.

Bertsimas (1992) tarafından STARP konusunda yapılan çalışmada, bütün potansiyel müşteriler için önce rota düzenlemesi yapılmakta, müşterilerin talep bilgilerine göre 2 strateji altında rota güncellemesi yapılması gerektiği önerilmektedir. İlk ve yeniden optimizasyon stratejileri kullanılarak problemi çözmeye çalışmıştır ve bu iki stratejinin performansını karşılaştırmıştır.

Literatürdeki çalışmalarda STARP'ın modellenmesi için genelde SPR yaklaşımının kullanıldığı görülmüştür. Dror, Laporte ve Trudeau (1989), STARP'1, stokastik çok aşamalı programlama problemi olarak ele almış ve modellemede SPR'yi kullanmışlardır. Rota devam ederken araç müşterilerin talebini karşılayamıyorsa, araç depoya gidip yükleme yaparak kaldığı müşteriden rotasına devam etmesini yardımcı eylem olarak kullanmışlardır. Problemi Markov Karar Zincirleri ile modellemişlerdir. Dror (1993) başka bir çalışmada da STARP'ın modellenmesi için SPR yaklaşımını kullanmıştır. Modelin çözümünün Hamilton Çevrimine karşılık geldiğini göstermiştir. Ayrıca, modelden elde edilen sonuçların karşılaştırılabilmesi için Markov karar modelini de geliştirmiştir. Laporte, Louveaux ve Van Hamme (2002) ise aynı problem için yardımcı eylem olarak depoya geri dönüşü (detour to depot - DTD) kullanan SPR yaklaşımı ile matematiksel modeli oluşturmuştur. Çalışmada taleplerin normal ve poisson olmak üzere 2 çeşit dağılıma sahip olduğunu kabul ederek, matematiksel programlamada her iki dağılımı da kullanmışlardır. Problemi kesin çözüm veren 
tam sayılı L-Shaped algoritmasıyla çözmüşlerdir. STARP'ın SPR yaklaşımıyla modellenmesinde depoya geri dönüş yardımcı eylemini kullanan bir başka çalışma Goodson, Ohlmann ve Thomas (2012) tarafından yapılmıştır. Problemde en iyi rotayı bulabilmek için rotalar belirlendikten sonra rotaların yeni alt turlarını oluşturmuşlardır.

Juan vd. (2011) de problemi depoya geri dönüş yardımcı eylemini kullanan SPR modellemişlerdir. Bu çalışmada STARP'ın araç kapasitesinin belirli bir yüzdesinde güvenlik stoğu bulunduran şeklini incelemişlerdir. Problemde toplam beklenen maliyet ile rota kırılmasının mevcut çözüme etkisi optimize etmeye çalışmışlardır. STARP'1 depoya geri dönüş yardımcı eylemini kullanarak modelleyen bir başka çalışma Zhu, Rousseau, Rei ve Li (2014) tarafından yapılmıştır. Ayrıca modele rotaların parçalı optimizasyonunu da eklemiş̧lerdir. Araştırmacılar müşterileri bazı varsayımlar altında gruplara ayırarak, iki araç ile müşteri hizmetlerinin karşılanabildiği durumu incelemiş̧lerdir.

Yang (1996) yaptığı çalışmada tek araçlı ve çok araçlı STARP'in modellenmesi SPR yaklaşımından faydalanmıştır. Problemde yardımcı eylem olarak koruyucu stoklama politikasını belirlemiş ve bu politikayı kullanarak araçların rotalarını oluşturmuştur. STARP için benzer bir yaklaşım, Biesinger, $\mathrm{Hu}$ ve Raidl (2016) tarafından da uygulanmıştır. Yaptıkları çalışmada, problemi koruyucu yeniden yükleme yardımcı eylemini kullanarak stokastik programlama ile modellemişlerdir. Bu politikaya göre araç stoksuz kalmadan yeniden yükleme için depoya gitmektedir. Problemin çözümü için Tam Sayılı L-Shaped algoritmasını kullanmışlardır.

Jabali, Rei, Gendreau ve Laporte (2014) STARP'1 iki aşamalı SPR ile modellemişlerdir. Bu çalışmada STARP'da planlanan rota maliyetini ve rota kırılması sonucu oluşacak maliyeti minimize etmeyi amaçlamışlardır. Problemin çözümü için L-shaped algoritmasını kullanmışlardır.

Dror (2016) bir başka çalışmada ise STARP için farklı yardımcı eylemler içeren stokastik programlama modelleri geliştirmiştir. Sabit kapasiteli araçta, müşteri talebinin karşılanamaması durumunda rota kırılması oluştuğunu varsaymış ve aracın depoya geri dönüş yardımcı eylemiyle problemin matematiksel modelini oluşturmuştur. Amaç verilen müşteri kümesinin talebini karşılamak için katlanılan maliyetin ve araç filosu maliyetinin minimize edilmesidir. 
STARP için yeni yardımcı eylem stratejisi Ak ve Erera (2007) tarafında önerilmiş olup, çift araçlı yardımcı eylem olarak adlandırdıkları strateji basit yardımcı eylemin ve depoya geri dönüş yardımcı eylemlerinin uzantısıdır. Eğer rotasına devam eden aracın kapasitesi aşılırsa, talebi karşılanamayan müşteriye diğer araç tarafından hizmet verilir. $\mathrm{Bu}$ aracın mevcut müşterilerle olan rotasının sonuna diğer araç tarafından hizmet verilememiş müşterilerin eklendiğini kabul etmişlerdir.

Laporte ve Loveaux (1990) yaptıkları çalışmada STARP'ın matematiksel modelini oluşturmak SPR yaklaşımını kullanmışlardır. Önerdikleri matematiksel modelde yardımcı eylem olarak koruyucu dönüş turlarını kullanmışlardır. Küçük boyuttaki problemin alt-üst sınırlarını belirlemek ve problemi çözmek için kesin çözüm yöntemlerinden faydalanmışlardır.

Literatürde STARP için yapılan bazı çalışmalarda ise SPR ile matematiksel modelinin geliştirilmesinin yanında, büyük boyuttaki problemlere makul sürede çözüm bulabilecek özellikte sezgisel ve metasezgisel çözüm yöntemleri de geliştirilmiştir. Yang, Mathur ve Ballou (2000) yaptıkları çalışmada tek araçlı ve çok araçlı STARP için SPR yaklaşımı kullanılarak matematiksel model geliştirmiştir. Problemde, depoda araç kalmadığında, araç depoya geri dönerek araca yeniden yükleme yapılmasını yardımcı eylem olarak almışlardır. Aracın rotasına, rota kırılmasının meydana geldiği yerden başlayarak devam edeceğini varsaymışlardır. Çalışmada hem tek araçlı hem de çok araçlı problem için toplam maliyeti minimize edecek sezgisel çözüm yöntemleri geliştirmişlerdir.

Gauvin, Desaulniers ve Gendreau (2014) STARP'a yeni kisitlar ekleyerek problemi SPR ile modellemişler, yardımcı eylem olarak ise depoya geri dönüş yardımcı eylemini kullanmışlardır. Uygun rotaları, bu çalışmada geliştirdikleri dinamik programlama algoritmasını kullanarak oluşturmuşlardır Depoya geri dönüş yardımcı eylemini kullanan bir başka çalışma Louveaux ve SalazarGonzalez (2018) tarafından yapılmıştır. Bu çalışmada müşteri taleplerindeki belirsizliklerden dolayı aracın tüm müşterilerin taleplerini karşılayamadığ kabul edilmiştir. Problemde araçların yükleme/boşaltma için depoya geri dönüş yapmasına izin verilmektedir. Bu geri dönüşs sayısının azaltılması için araçların koruyucu geri dönüşler yapabileceklerini kabul etmişlerdir. Problemin çözümü için kesin sonuçları elde eden, L-shaped algoritmasına dayanan dal ve kesme algoritmasını geliştirmişlerdir. Depoya geri dönüşü içeren daha güncel bir çalışma Hernandez, Gendreau, Jabali ve Rei (2019) tarafından yapılmıştır. 
Problemi iki aşamalı olarak SPR yaklaşımı ile modellemişlerdir. Aracın kapasitesi aşıldığında rota kırılması meydana geldiğini kabul etmişler ve bu durumda aracın depoya geri dönüp yeniden yükleme/boşaltma yaptığını ve rotaya kaldığı müşteriden devam ettiğini varsaymışlardır. Problemin çözümü için Yerel Dallanma Metasezgiselini geliştirmişlerdir.

Ismail ve Irhamah (2008) ise problemi koruyucu stoklama politikas1 yardımcı eylemini içeren SPR yaklaşımı ile modellemişlerdir. Modelin çözümü için Genetik Algoritma ve Tabu Arama yaklaşımlarını birleştiren hibrit bir algoritma geliştirmişlerdir. Geliştirdikleri algoritmayla diğer çözüm yöntemlerine göre daha iyi sonuçlar elde ettiklerini belirtmişlerdir. Biesinger, Hu ve Raidl $(2015,2018)$ de problemin modellenmesi için koruyucu stoklama politikası yaklaşımını kullanmıştır. Problemin çözümü için değişken komşu arama yaklaşımına dayanan bir algoritma önermişlerdir. Araştırmacılar başka bir çalışmalarında ise aynı problemin çözümü için genetik algoritmaya dayanan bir yaklaşım kullanmışlardır.

STARP yeniden yükleme yardımcı eylemini içeren yaklaşımla, Marinakis, Iordanidou ve Marinaki (2013) tarafından modellenmiştir. Bu çalışmada araştırmacılar rota kırılmasına izin vermemiş, araçtaki ürün miktarı için bir eşik değeri belirlemişlerdir. Eğer araçtaki ürün miktarı bu eşik değerinin altına düşerse araç koruyucu yeniden yükleme yapmak için depoya dönmektedir. Problemin çözümü için Parçacık Sürü Optimizasyonu algoritmasını kullanmışlardır. Pasha, Hoff ve Hvattum (2017) ise problemin çok dönemli ve farklı kapasitedeki araçların yer aldığı şeklini incelemişlerdir. Amaç, araç edinme maliyeti, rota maliyeti ve rota kırılmasından meydana gelen beklenen maliyetlerin toplamının minimize edilmesidir. Müşteriye yetersiz miktarda mal ile gidildiğinde rota kırılmasının meydana geldiğini ve aracın yeniden yükleme için depoya döndügünü varsaymışlardır. Problemi karışık tam sayılı programlama ile modellemişler ve çözümü için bir sezgisel algoritma geliştirmişlerdir.

Teodorovi'c ve Pavkovi'c (1992) STARP için SPR yaklaşımına dayanan bir matematiksel model geliştirmiştir. Problemde en fazla bir kırılmanın gerçekleşebileceği ve müşteri taleplerinin düzgün dağılıma sahip olduğu varsayımlarını kabul etmişlerdir. Problemin çözümü için tavlama benzetimi algoritmasını kullanmışlardır.

STARP'da araç kısıtlarını da dikkate alan bir çalışma Haugland, Ho ve Laporte (2007) tarafından yapılmıştır. Problemi SPR yaklaşımı ile 
modellemişlerdir. Her bir alt turdaki talebin araç kapasitesine eşit veya daha az olmasının sağlanmasını ve rotalama maliyetini minimize edecek alt turların planlanmasını yardımcı eylem olarak almışlardır. Problemin çözümü için Tabu Arama ve Çok Başlangıçlı Sezgiseli kullanmışlardır.

Wang, Lan ve Zhao (2017), lojistik hizmetlerinde karşılaşılan 2 aşamalı STARP'1 incelemişler ve problemi SPR yaklaşımını kullanarak modellemişlerdir. Amaç seyahat maliyetlerinin ve rota kırılması sonucu ortaya çıkan maliyetlerin minimize edilmesidir. Problemin çözümü için genetik algoritmaya dayanan bir yaklaşım geliştirmişlerdir.

Salavati-Khoshgahalb, Gendreau, Jabali ve Rei (2019a) yaptıkları çalışmada STARP'ı SPR yaklaşımı ile modellemişlerdir. Rota kırılması, araç rotasına devam ederken herhangi bir noktada aracın kapasitesi aşıldığında meydana gelmektedir. Bu rota kırılmalarında yardımcı eylemler kullanılarak rotayı uygun hale getirmeye çalışmışlardır. Ele alınan operasyonel kuralları tanımlamak ve planlanan rotada bu operasyonel kuralları uygulamak için yardımcı eylemleri kullanan sabit eşik temelli bir politika geliştirmişlerdir. Araştırmacılar yaptıkları bir başka çalışmada STARP'da müşteri taleplerinden dolayı araç kapasitesi aşıldığında rota kırılmalarının meydana geldiğini kabul etmişlerdir. Problemde yardımcı eylem olarak optimal yeniden yüklemeyi kullanmışlardır. Tam sayılı L-shaped algoritmasını, dal ve kesme algoritmasıyla uyarlayarak, STARP'ın çözümünde kullanmışlardır. Aynı yıl yaptıkları bir başka çalışmada ise STARP için depoya geri dönüş ve optimal yeniden yükleme yardımcı eylemlerini birleştiren yeni bir yardımcı eylem kullanarak problemin matematiksel modelini oluşturmuşlardır. Problemin çözümü için hibrit yardımcı eylem politikası altında kesin çözüm bulabilen bir algoritma geliştirmişlerdir (Salavati-Khosgahalb vd, 2019a, 2019b, 2019c).

Literatürde yapılan çalışmalarda, STARP'ın modellenmesi için CCP yaklaşımını kullanan araştırmacılar bulunmaktadır. Mendoza, Castanier, Gueret, Medaglia ve Velasco (2010) yaptıkları çalışmada çok bölmeli STARP'1 incelemişler ve problemi CCP yaklaşımını kullanarak modellemişlerdir. Problemin çözümü için genetik operatörleri içeren memetik algoritmayı ve yerel arama prosedürünü kullanmışlardır. Problemin modellenmesi için CCP yaklaşımını kullanan daha güncel bir çalışma, Dinh, Fukasawa ve Luedtka (2018) tarafindan yapılmıştır. Çalışmada her bir aracın kapasitesinin aşılması olasılığına sınırlama getiren, taleplerin stokastik olduğu ARP incelenmiştir. Problemin 
çözümü için dal-kesme ve fiyat algoritmasını kullanmışlardır ilk olarak bu algoritmayı deterministik ARP için uygulamışlar, daha sonra ise stokastik talepleri içerecek şekilde geliştirmişlerdir.

Literatürdeki bazı çalışmalarda ise SPR ve CCP yaklaşımlarının birlikte kullanılarak problemin matematiksel modelinin oluşturulduğu görülmektedir. Bunlardan ilki, Dror ve Trudeau (1986) tarafından STARP'ın modellemesi için yapılan çalışmadır. Modeli önce CCP yaklaşımı ile daha sonra ise SPR yaklaşımı ile modellemişlerdir. Yardımcı eylem olarak, rota kırılması oluştuğunda, kırılmanın meydana geldiği müşteri ve kalan diğer müşterilere bireysel olarak hizmet verilmesini almışlardır. Modeli çözmek için Clarke ve Wright'ın tasarruf algoritmasını probleme uyarlamışlardır. Stewart ve Golden (1983) de iki yaklaşımı birden kullanarak, STARP'ın matematiksel modelini oluşturmuştur. Modelde $\mathrm{k}$ rotasındaki her bir kırılmada sabit ceza katsayısı ve rota devam ederken herhangi bir noktada aracın kapasitesinin aşıldığı durumda birim talep için ceza katsayısını içeren yardımcı eylemleri kullanmışlardır. Küçük boyutlu problemlerin çözümü için Lagrange çarpanlarını kullanarak kesin çözümler elde etmişler, büyük boyuttaki problemlerin çözümü için ise Tasarruf algoritmasını kullanmışlardır. Laporte, Louveaux ve Mercury (1989) de problemi modellemek için iki yaklaşımı birlikte kullanmıştır. İlk olarak şans kısıtlı STARP'ın nasıl deterministik hale getirilebileceğini incelemişlerdir. Yardımcı Eylemli STARP'da ise rotadaki araçların beklenen maliyetini minimum yapmayı amaçlamışlardır. Yardımc1 eylem içeren çeşitli STARP'lar için kesin çözüm yöntemleri önermişlerdir.

Dror, Laporte ve Louveaux (1993), STARP'1 önce CCP yaklaşımı ile modellemişler ve kesin çözüm yöntemlerini kullanarak çözmeye çalışmışlardır. Daha sonra ise problemi SPR ile modellemişlerdir. Problemde araç rotada müşterilere hizmet verirken yalnız bir kere rota kırılmasına izin verilebileceği varsayımını kabul etmişlerdir. Modeli Gezgin Satıcı Problemi gibi düşünülerek elde ettikleri sıralama ile çözebilmişlerdir. Bastian ve Kan (1992) ise CCP ve SPR yaklaşımlarını kullanarak STARP için daha gerçekçi matematiksel model önerisinde bulunmuşlardır. Modelin çözümü için Clarke \& Wright'in Tasarruf Algoritmasına dayanan bir sezgisel geliştirmişlerdir.

STARP NP-hard özellikte olduğundan dolayı, literatürde daha çok problemin çözümüne yönelik çalışmaların yapıldığı görülmektedir. $\mathrm{Bu}$ çalışmaların çoğunda matematiksel model önerisinde bulunulmadı̆̆ 
problemin çözümüne yönelik yaklaşımlara yer verildiği görülmektedir. Özellikle son y1llarda bilgi ve iletişim teknolojilerindeki gelişmeyle paralel olarak, araştırmacıların daha kısa sürede problemi çözebilecek sezgisel ve metasezgisel yöntemlerin geliştirildiği çalışmalara yoğunlaştığı görülmektedir.

Bertsimas, Chervi ve Peterson (1995) yaptıkları çalışmada Olasılıklı Gezgin Satıcı problemi ile Olasılıklı Araç Rotalama Problemleri için Öklid düzlem versiyonlarını ve talepler gerçekleşmeden rotaları tasarlayan grafik tabanlı öncül sezgisellerini kullanmışlardır. Yaptıkları çalışmada bu sezgisellerden elde edilen sayısal sonuçları karşılaştırmışlardır.

Teng, Ong ve Huang (2003) ise problemin çözümü için aynı komşuluk yapılarını kullanan Tabu Arama, Tavlama Benzetimi ve Eşik Kabul yöntemlerini kullanmışlar, elde edilen sonuçları karşılaştırmışlar ve en iyi sonuçların Tabu Arama yöntemiyle elde edildiğini tespit etmişlerdir.

Bianchi vd. (2004), amaç olarak aracın beklenen seyahat mesafesini minimize edecek müşteri turlarının oluşturulması olarak belirlenen STARP'1 incelemiştir. Problemin çözümü için çeşitli sezgisel ve metasezgisel yöntemleri kullanmışlar ve elde ettikleri sonuçları karşılaştırmışlardır.

Moghaddam, Ruiz ve Sadjadi (2012) yaptıkları çalışmada STARP'da karşılanamayan müşteri taleplerinin neden olduğu maliyeti minimize etmeye çalışmışlardır. Problemi çözmek için Kuş Sürüsü Algoritmasını kullanmışlardır ve gerçek hayat problemlerini örnek alarak çözülen problemlerin optimuma çok yakın sonuçlar bulduğunu tespit etmişlerdir.

STARP'ın çözümü için bir başka çalışma ise Mendoza ve Villegas (2013) tarafindan yapılmıştır. Bu çalışmada, Gezgin Satıcı Problemi için kullanılan rassal sezgisele dayanan etkili bir sezgisel yaklaşım geliştirmişlerdir. $\mathrm{Bu}$ yaklaşımda tur bölümleme prosedürü ve örneklem içi bir dizi alt bölümler oluşturma formülasyonu ile çözüm alanını oluşturmuşlar ve örnek problemler için yüksek kalitede çözümler elde etmişlerdir.

Juan, Faulin, Jorba, Caceres, Marques (2013) STARP'ın etkili bir şekilde çözülebilmesi için Paralel \& Dağıtılmış Hesaplama Sistemleri yöntemini kullanmışlardır. $\mathrm{Bu}$ yaklaşımda müşteri taleplerindeki belirsizlik tutulan emniyet stokları yardımıyla karşılanmaktadır, yani araçların rotaları belirlenirken, araç kapasitesinin bir kısmı beklenmeyen taleplerin oluşturduğu acil durumlarla başa çıkabilmek için tutulan emniyet stoğuna ayrılmaktadır. Bu varsayımlar altında 
problemi geliştirdikleri Paralel \& Dağıtılmış Hesaplama Sistemleri yöntemi ile çözmüşlerdir.

Marinakis, Marinaki ve Spanou (2015) STARP'1 çözmek için Memetik Diferansiyel Evrim Algoritmasını kullanmışlardır. Geliştirilen algoritmanın yeteneğini artırmak için değişken komşu arama yöntemiyle birlikte kullanmışlardır.

Calvet, Bernaus, Travessat-Baro ve Juan (2016) ise heterojen araç filosunun kullanıldığı, tüm araç tiplerinin tüm müşterilere hizmet veremediği, asimetrik maliyetlerin yer aldığı STARP'1 incelemişlerdir. Problemin çözümü için ardışık yaklaşımlar yöntemine dayanan simheuristik metadolojisini kullanmışlardır.

Sarasola, Doerner, Schmid ve Alba (2016), stokastik ve dinamik taleplerin yer aldığı ARP'i incelemişlerdir. Problemde stokastik talepler araç müşterinin bulunduğu yere geldiğinde ortaya çıkmaktadır ve dinamik talepler ise daha önce bilinmeyen müşterilerden gelen taleplerden oluşmaktadır. Problemin çözümü için dinamik durumlara ve stokastik senaryolara uygun olarak geliştirilen değişken komşu arama algoritmasını kullanmışlardır.

Marinaki ve Marinakis (2016) geliştirdikleri ateşböceği sürüsü optimizasyonu algoritmasını STARP'ın çözümü için kullanmışlardır. Bu çalışmada, geliştirdikleri algoritmayla elde ettikleri sonuçları, diğer sezgisel yöntemlerle karşılaştırmışlar ve algoritmanın daha iyi sonuç verdiğini tespit etmişlerdir.

Liu, Kou ve Huang (2016) ise bulanık taleplerin yer aldığı ARP'1 ele almışlardır. Problemi bulanık kısıtlı programlama yaklaşımı ile modellemişler ve çözümü için hibrit karınca kolonisi optimizasyonu algoritmasını kullanmışlardır.

Luo, Qin, Zhang ve Lim (2016) STARP'1 çözebilmek ve rotanın beklenen maliyetini hesaplayabilmek için dinamik programlamaya dayanan öncelikli optimizasyonu kullanmışlardır. Problemin çözümü için uyarlamalı geniş komşu arama sezgiselini geliştirmişlerdir.

Subramanyam, Repoussis ve Gounaris (2018), farklı kapasitelerdeki araç filosunun yer aldığı STARP'1 incelemiştir. Problemin çözümünü, klasik dügüm ve komşu değişimi hareketlerini içeren bir komşu arama algoritmasıyla yapmışlardır.

Florio, Hartl ve Minner (2018), optimal yeniden yüklemeli STARP'1 inceleyen bir çalışma yapmıştır. Geliştirdikleri dal-fiyat-kesme algoritmasıyla, 
etkili bir etiketleme prosedürü uygulayarak, birden fazla aracın yer aldığ durum için uygun rotaları belirleyebilmişlerdir.

Gutierrez, Dieulle, Labadie ve Velasco (2018) STARP'1 çözebilmek için memetik algoritma ile Açgözlü Rassal Uyarlamalı Arama Prosedürünü birleştiren hibrit bir algoritma geliştirmişlerdir. Geliştirdikleri algoritmayı 40 örnek problemde test etmişler ve algoritmanın kaliteli ve etkili çözümler bulduğunu tespit etmişlerdir.

Festa, Pastore, Ferone, Juan, Bayliss (2018), STARP'ın çözümü için bağlı rassal açgözlü rassal adaptif arama prosedürü (GRASP) metasezgiselinin özelleştirilmiş halini kullanmışlardır. Bu çalışmada, sağlam ve rekabetçi çözümler elde etmek için iki aşamalı Monte Carlo simülasyonu ile GRASP'1 birleştiren hibrit bir algoritma oluşturmuşlardır. İlk aşamada, simülasyondan elde edilen optimum çözümler kümesi tanımlanmaktadır. İkinci aşamada ise umut veren çözümler simülasyon ile test edilerek en güvenilir çözümler belirlenmektedir. Buldukları en güvenilir çözümü ise nihai çözüm olarak almışlardır.

Arvianto, Saptadi, Budiawani, Nartadhi (2019), STARP'ın çözümü için 0-1 yer değiştirme tekniğine dayanan sıralı ekleme algoritmasını kullanmışlardır. Olasılıklı talep içeren problemin optimal çözümünü bulabilmek için simülasyon tekniklerini kullanmışlardır.

Literatürde yapılan çalışmalar incelendiğinde, süre kısıtını dikkate alan STARP'ın konusunda da çalışmalar yapıldığı görülmektedir. STARP'ın genişletilmiş hali olan tüm taleplerin gerçekleşmesi için tur süresinin uygulanabilir olduğu problem Erera, Morales ve Savelsbergh (2010) tarafindan ele alınmıştır. Geliştirdikleri problemi süre kısıtlı STARP olarak adlandırmışlar ve problemi SPR yaklaşımı ile modellemişlerdir. Bölünemeyen turlardan depoya geri dönüş yardımcı eylemini kullanmışlardır. Zaman kısıtlamasını içeren başka bir çalışma Mendoza, Rousseau ve Villegas (2016) tarafindan yapılmıştır. Problemi hem CCP yaklaşımı ile hem de SRP yaklaşımı ile iki aşamalı olarak modellemişlerdir. İlk aşamada toplam rota süresinin belirlenen eşik değerden küçük olması gerekmektedir. İkinci aşamada ise eşik değerinin aşıldığı durumlar için amaç fonksiyonuna ceza değişkeni eklenmektedir. Problemin amacı, rotadaki beklenen gecikmenin minimize edilmesidir. Goodson, Thomas ve Ohlmann (2015) benzer problemi incelemiş ve araçların uygun rotalarının belirlenmesi için yeniden yükleme yardımcı eylemine dayanan Rollout algoritmasını 
kullanmışlardır. Sabit bir rota boyunca, optimal yeniden stoklama miktarını hesaplayabilecek bir algoritma geliştirmişlerdir. Mendoza ve arkadaşları (2016) ise süre kısıtının yer aldığı STARP'ı çözümleyebilmek için iki strateji önermişlerdir. İlkinde, süre kısıtlamaları şans kısıtlı programlamayla ele alarak, maksimum sürenin aşılma olasılığının belirli bir eşikten düşük olacak şekilde olduğunu kabul etmişlerdir. İkincisinde ise süre kısıtlarının aşılmasını amaç fonksiyonuna ceza olarak eklemişlerdir. Problemlerin çözümü için GRASP’a dayanan bir yaklaşım geliştirmişlerdir.

Problemde her rotada süre limiti kısıtı bulunan ve araçların çok bölmeli özellikte olduğu STARP Goodson (2015) tarafından ele alınmıştır. Çözümün beklenen maliyetini hesaplayabilmek için tavlama benzetimindeki döngü sıralamasını esas alan bir yöntem geliştirmiştir, ancak bu yöntemin sadece talepler kesikli dağılıma sahip olduğunda kullanılabileceğini belirtmiştir.

Ulmer, Mattfeld, Hennig, Goodson (2015) belirli bir süre diliminde hizmet verilen müşteri sayısının maksimize edilmesini amaçlayan STARP'1 incelemişlerdir. Problemde uygun rotaların oluşturulabilmesi için rollout algoritmasını kullanmışlardır.

Literatürde yer alan bazı çalışmalarda ise robust özellikte olan STARP'in incelendiği görülmektedir. Sungur, Orderez ve Dessouky (2008) tarafindan robust STARP ele alınmıştır. Çalışmada sınırlı bir belirsizlik kümesine ait taleplerin robust olduğu tüm durumlar için uygun çözüm bulunmaktadır. Robust ARP için uygun çözüm olarak, tüm belirsiz parametreler en kötü değeri aldığında amaç fonksiyonunu optimize eden rotanın belirlenmesi olarak almışlardır. Robust STARP'ın bir başka versiyonu Gounaris, Wiesemann ve Floudas (2013) tarafından incelenmiştir. $\mathrm{Bu}$ problemde, taleplerin olasılık dağılımlarının bilinmediğini ancak taleplerin tüm olası gerçekleşme durumlarının bilindiğini varsaymışlardır. Problemi MillerTucker-Zemlin'den elde edilen öncelik formülasyonu ile modellemişlerdir.

Hem müşteri taleplerinin hem de müşterilerin stokastik olduğu ARP Gendreau, Laporte ve Seguin (1995) tarafından incelenmiştir. Problem için stokastik tam sayılı matematiksel model geliştirmişler ve probleme kesin çözüm bulabilecek bir algoritma önerisinde bulunmuşlardır.

Çok amaçlı STARP'da araştırmacılar tarafından ele alınan bir konu olmuştur. Yapılan çalışmada zaman kısıtlamaları ile araç kapasitesinin aşılmasının engellenmesi kısıtları altında, seyahat mesafesi, sürücü ücreti ve araç 
sayısının minimum hale getirilmesi amaçlanmaktadır. Problemin çözümü için rota simulasyonunu içeren çok amaçlı evrimsel algoritmayı kullanmışlardır (Tan, Cheong ve Goh, 2007).

\section{Tek Araçlı STARP Hakkında Yapılan Çalıșmalar}

STARP ile ilgili literatürde yer alan çalışmalar incelendiğinde, araştırmacıların genelde çok aracın yer aldığı problem türüne odaklandığı görülmektedir. Ancak bazı araştırmacılar, tek aracın rotasının belirlendiği STARP'1 de incelemişlerdir. Bu bölümde tek araçlı STARP konusunda yapılan çalışmalara yer verilmiştir. Jaillet ve Odoni (1988) tek araçlı STARP'1 incelemişler, bu problemde müşteri taleplerinin ya 0 ya da 1 olduğunu varsaymışlardır. Araştırmacılar yaptıkları çalışmada söz konusu problem için optimal çözüm bulunamayacağını belirtmişlerdir. Hjorring ve Holt (1999) ise benzer problemi, depoya geri gidiş yardımcı eylemini içeren SPR yaklaşımı ile modellemiştir. Yaptıkları çalışmada, araçtaki stok tükenmesini iki şekilde ele almışlardır. İlki normal stok tükenmesi, yani müşteri talebinin araçtaki kapasiteyle karşılanamadığı durumdur. Bu durumda araç yeniden yükleme için depoya döner ve rota kırılmasının oluştuğu yerden rotasına devam eder. Diğeri ise kesin stok tükenmesi, yani aracın belirli müşterilerin talebini karşılayacak kadar ürüne sahip olmasıdır. Yeniden yüklemeden sonra araç sonraki müşteriden rotasına devam etmektedir. Secomandi $(2000,2001)$ ise aynı problemin modellenmesinde, her rota kırılmasından sonra rotanın yeniden optimize edilmesi yardımcı eylemini kullanmıştır. Bu yaklaşım ile koruyucu stoklama politikasına göre daha küçük amaç fonksiyonu değerleri bulunabildiği, ancak bu yöntemin daha fazla işlem zamanı gerektirdiğini belirtmiştir Aynı problem için yaptığı bir başka çalışmada ise kesikli dağılıma sahip taleplerin yer aldığı problemi incelemiştir. Problemin modellenmesin SPR yaklaşımını kullanmıştır. Modellemede yardımcı eylem olarak ise depoya geri dönüş yardımcı eylemini kullanmıştır.

Bianchi vd. (2006) problemin modellenmesinde koruyucu yeniden yükleme içeren SPR yaklaşımını kullanmıştır $\mathrm{Bu}$ problemde, rota kırılması olmasa bile müşteri talebini karşılayacak yeniden yükleme için aracın depoya gidişine izin verildiğini varsaymışlardır. 
Tek araçlı STARP için dinamik programlama yaklaşımını kullanan çalışmalar da yapılmıştır. Novoa ve Storer (2009) maliyet hesabı için Monte Carlo Benzetimi ile iki aşamalı Rollout Algoritması kullanılmıştır. Yapılan hesaplamalarda ve işlem sürelerinde önemli derecede iyileşme meydana geldiğini belirtmişlerdir. Benzer problemde Monte Carlo benzetimini kullanan başka bir çalışma Rei, Gendreau ve Soriano (2010) tarafından yapılmıştır. Problemin modellenmesinde stokastik programlama yaklaşımından faydalanılmıs, yardımcı eylem olarak ise depoya geri dönüş eylemi alınmıştır. Zhang vd. (2013) problemin çözümü için değer fonksiyonu yaklaşımına dayanan dinamik programlama yaklaşımını kullanmışlardır. Bu dinamik programlamayı, arama tablolarını kullanarak geliştirmişlerdir.

Kyriakidis ve Dimitrakos (2015), taleplerin bilinen bir dağılım izlediği, rotaya bir depodan başlayan ve $\mathrm{n}$ adet müşteriye belirli bir sırayla hizmet veren bir aracın optimal rotasının belirlenmesi problemi üzerine çalışmışlardır. Problemde aracın yeniden yükleme için depoya geri dönebileceğini varsaymışlardır. Problemin çözümü için dinamik programlama yaklaşımını kullanmışlardır.

Secomandi ve Margot (2009), tek araçlı STARP'in çözümü için parçalı yeniden optimizasyon çözüm yöntemini kullanmışlardır. Bu yaklaşımda rotalama çoklu aşamadan oluşmaktadır ve müşteri taleplerinin gerçekleştirilmesine dayanmaktadır. Kalan araç kapasitesi ve ziyaret edilmemiş müşteriler kümesini kullanarak rotayı her bir aşamada yeniden optimize etmeye çalışmışlardır.

Kapasiteli aracın optimal rotasının oluşturulmaya çalışıldığ 1 , stokastik talep ve müşterilerin yer aldığı ARP Balaprakash, Birattari, Stützle ve Dorigo (2015) tarafından incelenmiştir. Yapılan çalışmada büyük boyuttaki problemlerin çözümü için yapay tahmin yaklaşımına dayanan bir yöntem geliştirmişlerdir.

Florio, Hartl ve Minner (2018) yaptıkları çalışmada tek araçlı STARP için optimum yüklemeyi içeren bir matematiksel model önermişlerdir. Modeli kesikli olasılık dağılımına sahip talepleri içeren Markov Karar Prosesi ile geliştirmişlerdir. Modeli karışı tam sayılı doğrusal programlama modeline dönüştürmüşler ve küçük boyuttaki problemler için modeli çözmüşlerdir.

Bartazzi ve Secomandi (2018) problemin çözümü için rollout algoritmasını kullanmışlardır. $\mathrm{Bu}$ çalışmada, işlem süresini düşürmek içiniçin yeniden yüklemeli STARP için herhangi bir rollout algoritmasını çalıştırırken aynı zamanda rota maliyetini de tahmin eden bir yaklaşım geliştirmişlerdir. 


\section{Zaman Pencereli STARP Konusunda Yapılan Çalışmalar}

STARP ile ilgili literatürde yapılan çalışmalar incelendiğinde, zaman penceresi kısıtını dikkate alan çok fazla çalışmanın bulunmadığı dikkat çekmektedir. STARP için zaman penceresi kısıtını içeren ilk çalışma Ong, Ang, Goh ve Deng (1997) tarafindan yapılmıştır. Bu çalışmada araştırmacılar Zaman Pencereli STARP (ZP_STARP) için CCP yaklaşımını kullanarak matematiksel model geliştirmişlerdir. Problemin çözümü için seçim kriterini önermişler ve sıralı bir sezgisel geliştirmişlerdir.

Literatürdeki çalışmalarda genelde ZP_STARP'ın SPR yaklaşımı ile modellendiği görülmektedir. Chang (2005), ZP_STARP'1 modellemek için SPR yaklaşımını kullanmıştır. Yardımcı eylem olarak kesin stok tükenmesi ve aracın kapasitesinin aşılmasını almıştır. Her iki durumda da aracın depoya geri döndügünü varsaymıştır. Erera, Savelsberg ve Uyar (2009) de problemi depoya geri dönüş yardımc1 eylemini içeren SPR ile modellemiştir. Eğer araç bir müşterinin talebini karşılayamazsa, aracın yeniden yükleme için depoya gittiğini kabul etmişlerdir. Lei, Laporte ve Guo (2011) da problemi SPR yaklaşımı ile modellemiştir. Problemde, gerçekleşen talep, herhangi iki düğüm arasında araç kapasitesini aşmışsa, zaman penceresinin sonucu olarak rota kırılması oluşmakta, aynı rotadaki kalan noktalar için ise zincirleme rota kırılması oluşturabilmektedir. Problemin çözümü için uyarlamalı geniş komşu arama algoritmasını geliştirmişlerdir. Zhang, Lam ve Chen (2016) de SPR yaklaşımını kullanmışlardır. Çalışmada aracın müşteriye erken varış ve geç varışlarına ilişkin kısıtlarını içerecek şekilde üç farklı yardımcı eylemi içeren matematiksel model sunulmuştur.

Soonpracha, Mungwattana ve Manisri (2015) sabit filo büyüklüğüne sahip, farklı araç tiplerinin yer aldığ1, karışık ZP_STARP'ı incelemişlerdir. Problemin çözümü için genetik algorimanın modifikasyonuyla, rotalar arası komşu arama yöntemiyle GRASP'1 birleştiren hibrit bir algoritma geliştirmişlerdir.

Gee, Arokiasami, Jiang ve Tan (2016), araç kapasitesini dikkate alan çok amaçlı ZP_STARP'ı incelemişlerdir. Problemin çözümü için yerel arama ve çok modlu mutasyon sezgisellerine dayanan ayrıştırma tabanlı çok amaçlı evrimsel algoritmayı geliştirmişlerdir. Goel, Maini ve Bansal (2019), stokastik müşteri talepleri ile stokastik servis sürelerinin yer aldığı çok amaçlı Zaman Pencereli ARP'1 incelemişlerdir. Çalışmada müşteri tatminini maksimize edecek ve aynı 
zamanda toplam ulaştırma maliyetini de minimize edecek şekilde problemi modellemişlerdir. Modelin çözümü için uyarlanmış karınca kolonisi optimizasyonu yaklaşımını kullanmışlardır.

$\mathrm{Hu}, \mathrm{Lu}$, Liu ve Zhang (2018) belirsiz talep ve servis süresi altındaki katı zaman pencereli ARP'1 inceleyen bir çalışma yapmıştır. Problemde yeni rotaya bağlı belirsizlik kümelerine dayanan robust optimizasyon modelini oluşturmuşlardır. Problemin çözümü için uyarlanmış değişken komşu arama sezgiseline dayanan iki aşamalı bir algoritma geliştirmişlerdir. İlk aşamada toplam seyahat mesafesi minimize ederken, ikinci aşamada ise araçların toplam rota sayısını minimize etmişlerdir. Robust yaklaşımı içeren bir başka çalışma Sun ve Wang (2018) tarafından yapılmıştır. Problemde, zaman penceresini aşan sapmaların toplamının minimizasyonu amaçlanmaktadır. Probleme robust optimale yakın çözüm bulabilmek için üst sezgisellerle birlikte genetik algoritmayla parçacık sürüsü optimizasyonunu birleştiren hibrit bir yöntem geliştirmişlerdir.

ZP_STARP konusunda gerçek hayat problemlerini dikkate alan çalışmalar da yapılmıştır. Lee, Lee ve Park (2012), teslim tarihlerinde ve seyahat sürelerinde/taleplerde belirsizlik durumu olan ARP için robust yaklaşımı kullanmıştır. $\mathrm{Bu}$ çalışmada her müşteri için bir teslim tarihi bulunduğunu belirtmişler ve bu tarihi zaman penceresinin özel bir durumu olarak kabul etmişlerdir. Amaç mesafelere bağlı belirsizlik içeren toplam deterministik uzaklığın minimize edilmesidir.

Soğuk zincir lojistiğinin yer aldığ STARP Xiangguo ve Manying (2015) tarafından ele alınmıştır. Yaptıkları çalışmada ilk önce soğuk zincir lojistiğini analiz etmişler daha sonra ise karışı zaman penceresini içeren matematiksel modeli oluşturmuşlardır. Modeli uyarlanmış genetik algoritma yaklaşımı ile çözmüşlerdir.

Zhang, Lam ve Chen (2016), tam zamanında teslimat gerektiren durumları, ZP_STARP olarak düşünmüşlerdir. Zamanında teslimatı farklı açılardan ele alan üç model önermişlerdir. İlkinde, beklenen toplam maliyeti minimum yapacak teslimat rotasının oluşturulmasını, ikincide müşterilere zamanında teslimat yapılma olasılıkları toplamının maksimize edilmesini, üçüncüde ise müşterilere zamanında teslimatın yanında toplam maliyetin en aza indirilmesini amaçlamışlardır. Saint-Guillain, Solnon ve Deville (2017) yaptıkları çalışmada gerçek hayat problemlerinde karşılaşılan, verilerdeki belirsizliği göz önüne alan, 
müşteri taleplerinin tam olarak bilinmediği, statik ve stokastik ARP'1 modellemiş ve çözmüşlerdir. Problemin modellenmesi için SPR yaklaşımını kullanmışlardır ve çözüm için ise yerel arama bazlı bir algoritma geliştirmişlerdir.

Qin Ye, Cheng, Zhao ve Ni (2017), belirsiz taleplerin normal dağılıma uyduğunu kabul ederek, araç sayısının kısıtlı olduğu ve belirsiz taleplerin yer aldığı acil servis araç rotaların oluşturulması için bir optimizasyon modelini geliştirmişlerdir. Problemde hastaların acil servis taleplerinin karşılanabilmesi için zaman penceresi kısıtını dikkate almışlardır. Problemin çözümü için genetik algoritmaya dayanan bir yaklaşım kullanmışlardır.

\section{Stokastik Talepli Çok Depolu ARP Hakkında Yapılan Çalışmalar}

Literatürde yapılan çalışmalar incelendiğinde, müşterilere birden fazla depodan hizmet verilen ARP'ın da yaygın olarak çalışıldığı görülmektedir. Ancak stokastik talebi içeren Çok Depolu ARP'ın araştırmacılar tarafından çok fazla çalışılmadığı tespit edilmiştir. Tillman (1969) birden fazla deponun yer aldığı ve müşteri taleplerinin poisson dağılımını izlediği Çok Depolu Stokastik Talepli Araç Rotalama Problemini (ÇD_STARP) ele almıştır. Tilmann bu problemin çözümü için Clarke \& Wright'ın tasarruf algoritmasına dayanan bir sezgisel yöntem önermiştir.

Calvet, Juan, Schefers (2015) ST_ÇDARP'1 SPR yaklaşımı ile modellemişlerdir. Yardımcı eylem olarak güvenlik stokunun bulundurulmasını kullanmışlardır. Problemin çözümü için iteratif yerel arama ve Monte Carlo Benzetimini içeren bir algoritma kullanmışlardır. Calvet, Wang, Juan ve Bove (2019) ise sınırlı filonun yer aldığı, yani sınırlı depo kapasiteli, ÇD_STARP'1 SPR yaklaşımı ile modellemişlerdir. Problemin çözümü için Monte Carlo Benzetimi ile metasezgisel algoritmaları birleştiren bir algoritma önermişlerdir.

Chan, Carter ve Burnes (2001) yaptıkları çalışmada çok depolu, çok araçlı konum rotalama problemini incelemişlerdir. Burada müşteri talepleri, araç konum rotalaması devam ederken talep düğümüne gelmeden önce belirlenmektedir. Problemde taleplerin beklenen değerlerini, önceki müşterinin talep bilgisini kullanarak belirlemişlerdir.

Tatarakis ve Minis (2009), tek araçlı çok depolu, çok ürünlü stokastik talepli ARP üzerine çalışmıştır. Her bir ürünün kendine ait araç bölmesinde saklandığı durum ile tüm ürünlerin aracın tek bölmesinde tutulduğu durumu ele 
almışlardır. Beklenen rotalama maliyetini minimize etmek için dinamik programlama yaklaşımını kullanmışlardır.

Zuhori, Peya ve Mahmud (2012), ÇD_STARP'1 çözmek için 3 fazlı bir yöntem geliştirmişlerdir. İlk olarak en yakın komşu arama yöntemiyle müşterilerin sınıflandırmasını yapmışlardır. Daha sonra alt kümelerin toplanması yöntemini araçların rotalaması için kullanmış ve son olarak aç gözlü algoritmayı kullanarak rotaları optimize etmişlerdir.

Uslu, Çetinkaya ve İşleyen (2017) yaptıkları çalışmada, insani yardım malzemelerinin en kısa sürede ve gerekli miktarda ulaştırılabilmesi için insani yardım lojistiği faaliyetini, birden çok deponun yer aldığı ve taleplerin belirli olmadığı, ÇD_STARP şeklinde ele almışlardır. Problemi CCP yaklaşımını kullanarak modellemişlerdir. Oluşturdukları matematiksel modeli doğrusallaştırdıktan sonra Ankara ili için çözmüşlerdir.

Christiansen, Eglese, Letchford, Lysgarard (2016), tüm müşterilerin taleplerini karşılayabilecek depo kapasitesinin sınırsız olduğu ÇD_STARP'1 incelemişlerdir. Problemde araç kapasitesinin sınırsız olduğunu varsaymışlardır. Problemin çözümü için Dal-Fiyat-Kesme algoritmasını geliştirmişlerdir.

\section{Stokastik Talepli Topla Dağıt / Eş Zamanlı Topla Dağıt ARP Hakkında Yapılan Çalışmalar}

Literatürde STARP için yapılan çalışmalar incelendiğinde, halen stokastik talepli topla dağıt ve eş zamanlı topla dağıt araç rotalama problemi (ST_TD_ARP / ST_ETD_ARP)konusunda çok fazla çalışma yapılmadığı tespit edilmiştir. Bu bölümde yapılan az sayıda çalışma hakkında bilgi verilmiştir.

Hou ve Zhou (2010) yaptıkları çalışmada hem stokastik talebin hem de belirsiz servis süresinin yer aldığı Stokastik Eş Zamanli Topla Dağıt ARP'1 incelemişlerdir. Problemi CCP yaklaşımını kullanarak modellemişlerdir. Problemde rota optimizasyonunun sağlanması için genetik algoritmayı kullanmışlardır. Aynı yıl içinde Hou, Zhou ve Zhao (2010) yaptıkları bir başka çalışmada belirsiz talepli ve servis süreli eş zamanlı topla dağıt araç rotalama problemini ele almışlardır. Problemin çözümü için yeni bir mutasyon operatörü geliştirmişler ve diferansiyel evrim algoritmasını kullanmışlardır. Araç kapasitesinin belli bir miktara kadar aşılabileceğini varsaymışlar ve bu miktar aşıldığı takdirde ceza miktarını amaç fonsiyonuna eklemişlerdir. Hou ve Zhou 
(2013) bir başka çalışmada benzer problem için stokastik programlama modeli geliştirmişlerdir. Problemin amacı rota optimizasyonun sağlanmasıdır. Bu amacı gerçekleştirmek için de sıra bazlı uygulamayı dikkate alan Kesikli Diferansiyel Evrim Algoritmasını geliştirmişlerdir.

Minis ve Tatarakis (2011) yaptıkları çalışmada, ST_TD_ARP'1 incelemişlerdir. Problemde aracın belirli bir müşteri sırasını takip etmesi gerektiği varsayılmıştır ve gereken durumlarda aracın yükleme/ boşaltma için depoya geri dönmesine izin verilmektedir. Problemin amacı tüm müşterilere hizmet verilmesi ve seyahat maliyetinin minimize edilmesidir.

Wang ve Qiu (2011) ST_ETD_ARP'ın çözümü için çapraz entropi yöntemine dayanan etkili bir algoritma geliştirmişlerdir. Geliştirilen algoritmanın etkinliğini belirlemek için literatürde bulunan örnek problemleri çözmüşler ve geliştirdikleri algoritmanın iyi sonuçlar bulduğunu tespit etmişlerdir.

Dimitrakos ve Kyriakidis (2015) yaptıkları çalışmada, sürekli rassal topladağıt müşteri taleplerinin yer aldığı tek araçlı ve müş̧erilere belirli sırada hizmet verilen ARP'ı incelemişlerdir. Problemin çözümü için kesin sonuç bulan, dinamik programlama yaklaşımını kullanmışlardır.

Berhan (2016) ise yaptığı çalışmada, Etiyopya'daki şehiriçi otobüs hatlarındaki, otobüslere binen inen müşterileri dikkate alarak oluşturduğu problemi, gerçek verileri de dikkate alarak problemi ST_ETD_ARP olarak modellemiştir. Geliştirdiği model Clarke ve Wright'ın tasarruf algoritmasıyla çözmüştür.

Zaman penceresi, çizelgelenmiş durumlar ve stokastik taleplerin yer aldığ 1 topla dağıt ARP Ghilas, Demir ve Woensel (2016) tarafından incelenmiştir. Problemin çözümü için senaryo bazlı örnek ortalama yaklaşımını geliştirmişlerdir. Literatürdek örnek problemleri kullanarak, geliştirilen algoritmayla bulunan sonuçlar ile geniş komşu arama sezgiseli ile bulunan sonuçları karşılaştırmışlardır.

Zhu ve Sheu (2018) yaptıkları çalışmada, stokastik talepleri olan ürünleri toplayan ve teslim eden bir araç filosunun başlangıç rotalarını belirlemeye çalışmışlardır. Tam rota kırılması ve yarı rota kırılmasını tanımlayarak, rotadaki seyahat maliyetinin minimize etmeyi amaçlamışlardır. Problemin çözümü için geniş komşu arama yaklaşımını kullanmışlardır. 


\section{STARP Hakkında Yapılan Çalışmaların Değerlendirilmesi}

$\mathrm{Bu}$ çalışmada STARP konusunda ayrıntılı bir literatür taramasına yer verilmiştir. Yapılan çalışmalar incelendiğinde problemin daha çok tek aracın veya çok aracın bulunması, araçların tek depodan veya çok depodan hizmet vermesi, zaman penceresinin bulunması, araçlarla müşterilerin dağıtma talepleri veya topla/dağıt taleplerinin karşılanması kısıtlarını içerecek şekilde çalışıldığı tespit edilmiştir. Yapılan çalışmalarda genelde söz konusu kısıtların yalnız birini içeren problemler incelenmiş olup, az sayıda çalışmada ise stokastik talepli zaman pencereli topla dağıt araç rotalama problemi, stokastik talepli zaman pencereli çok depolu araç rotalama problemi gibi iki kısıtın birlikte ele alındığı tespit edilmiştir. Bu çalışmada, Stokastik Talepli Araç Rotalama Problemi konusunda yapılan çalışmalarda en çok ele alınan kısıtlar ile ilgili bir sınıflandırma yapılmış, çalışmalarda ele alınan problemlerin daha kolay karşılaştırılabilmesi için özet bir tablo olarak Tablo 1 oluşturulmuştur. Literatürdeki çalışmaları incelediğimizde genelde çok araçlı, tek depolu, sadece dağıt kısıtlarını içeren araç rotalama problemine değişik kısıtlar eklenerek çalışmalar yapıldığı dikkat çekmektedir. Ancak literatürdeki az sayıda çalışmada stokastik talepli tek araçlı çok depolu ARP veya stokastik talepli tek araçlı zaman pencereli ARP gibi birden fazla kısıtın değiştirildiği problemlerin incelendiği görülmektedir. Tablo 1'i incelediğimizde yapılan çalışmalarda genelde bu kısıtlardan yalnız birinin dikkate alındığı, birden fazla kısıtın ise yalnız birkaç çalışmada ele alınmış olduğu dikkat çekmektedir.

Literatürde yapılan çalışmalar dikkate alındığında en çok çalışmanın çok araçı STARP konusunda yapıldığı görülmektedir. Literarütrde STARP konusunda günümüze kadar yapılmış olan 101 adet çalışma incelenmiş ve bu çalışmalarda en çok hangi kısıtlar altındaki problemlerin incelendiğini tespit edebilmek için Şekil 1 oluşturulmuştur. Şekil incelendiğinde STARP konusunda literatürde en fazla Çok Araçlı STARP konusunda çalışma yapıldığı görülmektedir. STARP konusunda bilinen ilk çalışma Tillman tarafindan çok deponun yer aldığı problem için yapılmasına rağmen, literatürde en az çalışmanın ÇD_STARP konusunda yapıldığı dikkat çekicidir. 


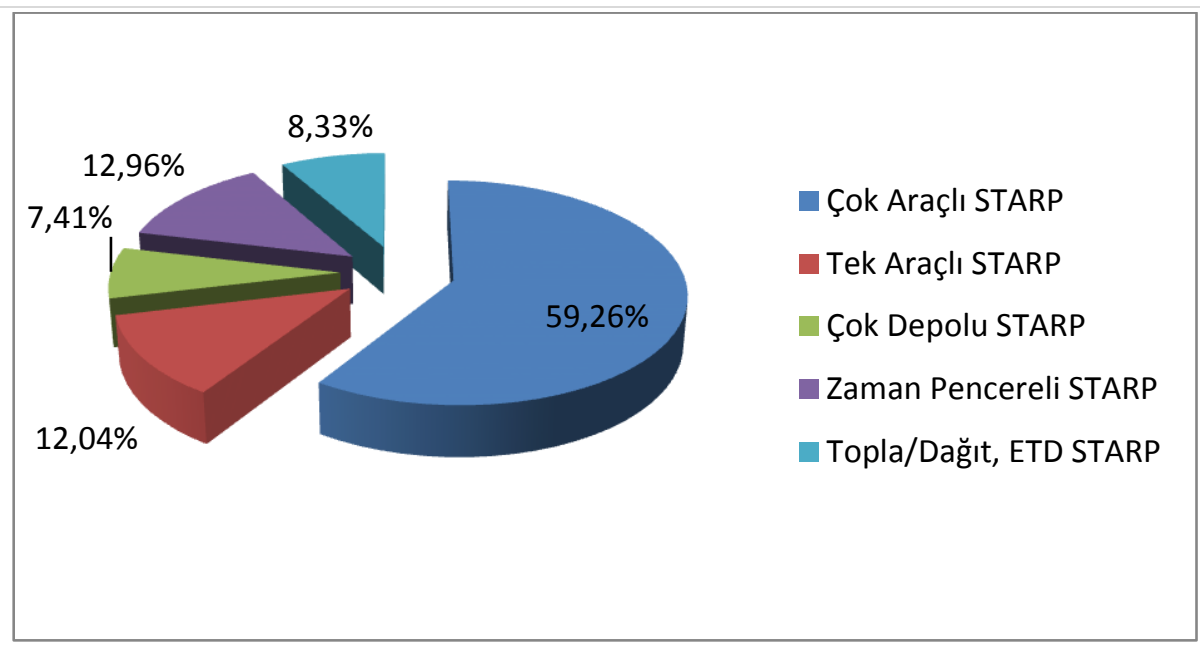

Şekil 1: Literatürde STARP Çeşitleri Hakkında Yapılan Çalışmaların Karşıllaştırılması.

Tablo 1: STARP Hakkında Yapılan Çalışmaların Değerlendirilmesi

\begin{tabular}{|l|l|l|l|l|l|l|l|l|l|}
\hline \multicolumn{1}{|c|}{ Yazar } & Y1lı & $\begin{array}{c}\text { Tek } \\
\text { Depolu }\end{array}$ & $\begin{array}{c}\text { Çok } \\
\text { Depolu }\end{array}$ & $\begin{array}{c}\text { Zaman } \\
\text { Pencereli }\end{array}$ & $\begin{array}{c}\text { Tek } \\
\text { Araçlı }\end{array}$ & $\begin{array}{c}\text { Çok } \\
\text { Araçlı }\end{array}$ & $\begin{array}{c}\text { Sadece } \\
\text { Dağıt }\end{array}$ & $\begin{array}{c}\text { Topla } \\
- \\
\text { Dağıst }\end{array}$ & $\begin{array}{c}\text { Zamanlı } \\
\text { Topla - } \\
\text { Dağıt }\end{array}$ \\
\hline Tillman & 1969 & & $\checkmark$ & & & $\checkmark$ & $\checkmark$ & & \\
\hline $\begin{array}{l}\text { Stewart ve } \\
\text { Golden }\end{array}$ & 1983 & $\checkmark$ & & & & $\checkmark$ & $\checkmark$ & & \\
\hline $\begin{array}{l}\text { Dror ve } \\
\text { Trudeau }\end{array}$ & 1986 & $\checkmark$ & & & & $\checkmark$ & $\checkmark$ & & \\
\hline $\begin{array}{l}\text { Jaillet ve } \\
\text { Odoni }\end{array}$ & 1988 & $\checkmark$ & & & & $\checkmark$ & $\checkmark$ & & \\
\hline Laporte vd. & 1989 & $\checkmark$ & & & & $\checkmark$ & $\checkmark$ & & \\
\hline Dror vd. & 1989 & $\checkmark$ & & & & $\checkmark$ & $\checkmark$ & & \\
\hline $\begin{array}{l}\text { Laporte ve } \\
\text { Louveaux }\end{array}$ & 1990 & $\checkmark$ & & & & $\checkmark$ & $\checkmark$ & & \\
\hline Bertsimas & 1992 & $\checkmark$ & & & & $\checkmark$ & $\checkmark$ & & \\
\hline $\begin{array}{l}\text { Bastian ve } \\
\text { Kan }\end{array}$ & 1992 & $\checkmark$ & & & & $\checkmark$ & $\checkmark$ & & \\
\hline $\begin{array}{l}\text { Teodorovi'c } \\
\text { ve Pavkovi'c }\end{array}$ & 1992 & $\checkmark$ & & & & $\checkmark$ & $\checkmark$ & & \\
\hline Dror & 1993 & $\checkmark$ & & & & $\checkmark$ & $\checkmark$ & & \\
\hline Dror vd. & 1993 & $\checkmark$ & & & & $\checkmark$ & $\checkmark$ & & \\
\hline $\begin{array}{l}\text { Bertsimas } \\
\text { vd. }\end{array}$ & 1995 & $\checkmark$ & & & & $\checkmark$ & $\checkmark$ & & \\
\hline Yang & 1996 & $\checkmark$ & & & $\checkmark$ & $\checkmark$ & $\checkmark$ & & \\
\hline
\end{tabular}


Tablo 2 (devamı): STARP Hakkında Yapılan Çalışmaların Değerlendirilmesi

\begin{tabular}{|c|c|c|c|c|c|c|c|c|c|}
\hline Yazar & Y1l1 & $\begin{array}{c}\text { Tek } \\
\text { Depolu }\end{array}$ & $\begin{array}{l}\text { Çok } \\
\text { Depolu }\end{array}$ & $\begin{array}{l}\text { Zaman } \\
\text { Pencereli }\end{array}$ & $\begin{array}{c}\text { Tek } \\
\text { Araçlı }\end{array}$ & $\begin{array}{c}\text { Çok } \\
\text { Araçl1 }\end{array}$ & $\begin{array}{c}\text { Sadece } \\
\text { Dağıt }\end{array}$ & $\begin{array}{c}\text { Topla } \\
- \\
\text { Dağıt } \\
\end{array}$ & $\begin{array}{c}\text { Eş } \\
\text { Zamanlı } \\
\text { Topla - } \\
\text { Dağıt }\end{array}$ \\
\hline Ong vd. & 1997 & $\checkmark$ & & $\checkmark$ & & $\checkmark$ & $\checkmark$ & & \\
\hline $\begin{array}{l}\text { Hjorring ve } \\
\text { Holt }\end{array}$ & 1999 & $\checkmark$ & & & $\checkmark$ & & $\checkmark$ & & \\
\hline Yang vd. & 2000 & $\checkmark$ & & & $\checkmark$ & $\checkmark$ & $\checkmark$ & & \\
\hline Secomandi & 2000 & $\checkmark$ & & & $\checkmark$ & & $\checkmark$ & & \\
\hline Secomandi & 2001 & $\checkmark$ & & & $\checkmark$ & & $\checkmark$ & & \\
\hline Chan vd. & 2001 & & $\checkmark$ & & $\checkmark$ & & $\checkmark$ & & \\
\hline Laporte vd. & 2001 & $\checkmark$ & & & & $\checkmark$ & $\checkmark$ & & \\
\hline Teng vd. & 2003 & $\checkmark$ & & & & $\checkmark$ & $\checkmark$ & & \\
\hline Bianchi vd. & 2004 & $\checkmark$ & & & & $\checkmark$ & $\checkmark$ & & \\
\hline Chang & 2005 & $\checkmark$ & & $\checkmark$ & & $\checkmark$ & $\checkmark$ & & \\
\hline Bianchi vd. & 2006 & $\checkmark$ & & & $\checkmark$ & & $\checkmark$ & & \\
\hline Tan vd. & 2007 & $\checkmark$ & & & & $\checkmark$ & $\checkmark$ & & \\
\hline Ak ve Erera & 2007 & $\checkmark$ & & & & $\checkmark$ & $\checkmark$ & & \\
\hline $\begin{array}{l}\text { Haugland } \\
\text { ve Ho }\end{array}$ & 2007 & $\checkmark$ & & & & $\checkmark$ & $\checkmark$ & & \\
\hline $\begin{array}{ll}\text { Ismail ve } \\
\text { Irhameh }\end{array}$ & 2008 & $\checkmark$ & & & & $\checkmark$ & $\checkmark$ & & \\
\hline Sungur vd. & 2008 & $\checkmark$ & & & & $\checkmark$ & $\checkmark$ & & \\
\hline Erera vd. & 2009 & $\checkmark$ & & $\checkmark$ & & $\checkmark$ & $\checkmark$ & & \\
\hline $\begin{array}{ll}\text { Novoa } & \text { ve } \\
\text { Storer } & \\
\end{array}$ & 2009 & $\checkmark$ & & & & $\checkmark$ & $\checkmark$ & & \\
\hline $\begin{array}{l}\text { Tatarakis ve } \\
\text { Minis }\end{array}$ & 2009 & & $\checkmark$ & & $\checkmark$ & & $\checkmark$ & & \\
\hline $\begin{array}{l}\text { Secomandi } \\
\text { ve Margot }\end{array}$ & 2009 & $\checkmark$ & & & & $\checkmark$ & $\checkmark$ & & \\
\hline $\begin{array}{l}\text { Hou ve } \\
\text { Zhou }\end{array}$ & 2010 & $\checkmark$ & & & $\checkmark$ & & & & $\checkmark$ \\
\hline Hou vd. & 2010 & $\checkmark$ & & & $\checkmark$ & & & & $\checkmark$ \\
\hline $\begin{array}{l}\text { Mendoza } \\
\text { vd. }\end{array}$ & 2010 & $\checkmark$ & & & & $\checkmark$ & & & \\
\hline Rei vd. & 2010 & $\checkmark$ & & & $\checkmark$ & & $\checkmark$ & & \\
\hline Erera vd. & 2010 & $\checkmark$ & & & & $\checkmark$ & $\checkmark$ & & \\
\hline Lei vd. & 2011 & $\checkmark$ & & $\checkmark$ & & $\checkmark$ & $\checkmark$ & & \\
\hline Juan vd. & 2011 & $\checkmark$ & & & & $\checkmark$ & $\checkmark$ & & \\
\hline $\begin{array}{l}\text { Minis ve } \\
\text { Tatarikis }\end{array}$ & 2011 & $\checkmark$ & & & & $\checkmark$ & & $\checkmark$ & \\
\hline $\begin{array}{l}\text { Wang ve } \\
\text { Qiu }\end{array}$ & 2011 & $\checkmark$ & & & & $\checkmark$ & & & $\checkmark$ \\
\hline $\begin{array}{l}\text { Moghadda } \\
\text { m vd. }\end{array}$ & 2012 & $\checkmark$ & & & & $\checkmark$ & $\checkmark$ & & \\
\hline
\end{tabular}


Tablo 3 (devamı): STARP Hakkında Yapılan Çalışmaların Değerlendirilmesi

\begin{tabular}{|c|c|c|c|c|c|c|c|c|c|}
\hline Yazar & Y1l1 & $\begin{array}{c}\text { Tek } \\
\text { Depolu }\end{array}$ & $\begin{array}{l}\text { Çok } \\
\text { Depolu }\end{array}$ & $\begin{array}{c}\text { Zaman } \\
\text { Pencereli }\end{array}$ & $\begin{array}{c}\text { Tek } \\
\text { Araçlı }\end{array}$ & $\begin{array}{l}\text { Çok } \\
\text { Araçlı }\end{array}$ & $\begin{array}{c}\text { Sadece } \\
\text { Dağıt }\end{array}$ & $\begin{array}{c}\text { Topla } \\
- \\
\text { Dağıt }\end{array}$ & $\begin{array}{c}\text { Eş } \\
\text { Zamanlı } \\
\text { Topla - } \\
\text { Dağıt }\end{array}$ \\
\hline $\begin{array}{l}\text { Goodson } \\
\text { vd. }\end{array}$ & 2012 & $\checkmark$ & & & & $\checkmark$ & $\checkmark$ & & \\
\hline Zuhori vd. & 2012 & & $\checkmark$ & & $\checkmark$ & & $\checkmark$ & & \\
\hline Lee vd. & 2012 & $\checkmark$ & & $\checkmark$ & & $\checkmark$ & $\checkmark$ & & \\
\hline $\begin{array}{l}\text { Mendoza ve } \\
\text { Villegas }\end{array}$ & 2013 & $\checkmark$ & & & & $\checkmark$ & $\checkmark$ & & \\
\hline $\begin{array}{l}\text { Marinakis } \\
\text { vd. }\end{array}$ & 2013 & $\checkmark$ & & & & $\checkmark$ & $\checkmark$ & & \\
\hline Juan vd. & 2013 & $\checkmark$ & & & & $\checkmark$ & $\checkmark$ & & \\
\hline $\begin{array}{l}\text { Gournais } \\
\text { vd. }\end{array}$ & 2013 & $\checkmark$ & & & & $\checkmark$ & $\checkmark$ & & \\
\hline Jabali vd. & 2014 & $\checkmark$ & & & & $\checkmark$ & $\checkmark$ & & \\
\hline Zho vd. & 2014 & $\checkmark$ & & & & $\checkmark$ & $\checkmark$ & & \\
\hline Gauvin vd. & 2014 & $\checkmark$ & & & & $\checkmark$ & $\checkmark$ & & \\
\hline Calvet vd. & 2015 & & $\checkmark$ & & & $\checkmark$ & $\checkmark$ & & \\
\hline Goodson & 2015 & $\checkmark$ & & & & $\checkmark$ & $\checkmark$ & & \\
\hline $\begin{array}{l}\text { Goodson } \\
\text { vd. }\end{array}$ & 2015 & $\checkmark$ & & & & $\checkmark$ & $\checkmark$ & & \\
\hline Ulmer vd. & 2015 & $\checkmark$ & & & & $\checkmark$ & $\sqrt{ }$ & & \\
\hline $\begin{array}{l}\text { Mendoza } \\
\text { vd. }\end{array}$ & 2015 & $\checkmark$ & & & & $\checkmark$ & $\checkmark$ & & \\
\hline $\begin{array}{l}\text { Marinakis } \\
\text { vd. }\end{array}$ & 2015 & $\sqrt{ }$ & & & & $\checkmark$ & $\sqrt{ }$ & & \\
\hline $\begin{array}{l}\text { Kyriakidis } \\
\text { ve } \\
\text { Dimitrakos }\end{array}$ & 2015 & $\checkmark$ & & & $\sqrt{ }$ & & $\checkmark$ & & \\
\hline $\begin{array}{l}\text { Soonpracha } \\
\text { vd. }\end{array}$ & 2015 & $\checkmark$ & & & & $\checkmark$ & $\sqrt{ }$ & & \\
\hline $\begin{array}{l}\text { Dimitrakos } \\
\text { ve } \\
\text { Kyriakidis }\end{array}$ & 2015 & $\checkmark$ & & & $\checkmark$ & & & $\checkmark$ & \\
\hline $\begin{array}{l}\text { Xiangguo } \\
\text { ve Manying }\end{array}$ & 2015 & $\checkmark$ & & $\checkmark$ & & $\checkmark$ & $\checkmark$ & & \\
\hline $\begin{array}{l}\text { Biesinger } \\
\text { vd. }\end{array}$ & 2015 & $\checkmark$ & & & & $\checkmark$ & $\checkmark$ & & \\
\hline $\begin{array}{l}\text { Balaprakash } \\
\text { vd. }\end{array}$ & 2015 & $\checkmark$ & & & $\checkmark$ & & $\checkmark$ & & \\
\hline $\begin{array}{l}\text { Christiansen } \\
\text { vd. }\end{array}$ & 2016 & & $\checkmark$ & & & $\checkmark$ & $\checkmark$ & & \\
\hline Sarasola vd. & 2016 & $\checkmark$ & & & & $\checkmark$ & $\checkmark$ & & \\
\hline Dror & 2016 & $\checkmark$ & & & & $\checkmark$ & $\checkmark$ & & \\
\hline $\begin{array}{l}\text { Marinaki ve } \\
\text { Marinakis }\end{array}$ & 2016 & $\checkmark$ & & & & $\checkmark$ & $\checkmark$ & & \\
\hline
\end{tabular}


Tablo 4 (devamı): STARP Hakkında Yapılan Çalışmaların Değerlendirilmesi

\begin{tabular}{|c|c|c|c|c|c|c|c|c|c|}
\hline Yazar & Y1l & $\begin{array}{c}\text { Tek } \\
\text { Depolu }\end{array}$ & $\begin{array}{l}\text { Çok } \\
\text { Depolu }\end{array}$ & $\begin{array}{c}\text { Zaman } \\
\text { Pencereli }\end{array}$ & $\begin{array}{c}\text { Tek } \\
\text { Araçlı }\end{array}$ & $\begin{array}{l}\text { Çok } \\
\text { Araçlı }\end{array}$ & $\begin{array}{c}\text { Sadece } \\
\text { Dağıt }\end{array}$ & $\begin{array}{c}\text { Topla } \\
- \\
\text { Dağıt } \\
\end{array}$ & $\begin{array}{c}\text { Eş } \\
\text { Zamanlı } \\
\text { Topla - } \\
\text { Dağıt }\end{array}$ \\
\hline Zhang vd. & 2016 & $\checkmark$ & & $\checkmark$ & & $\checkmark$ & $\checkmark$ & & \\
\hline Berhan & 2016 & $\checkmark$ & & & & $\checkmark$ & & & $\checkmark$ \\
\hline Luo vd. & 2016 & $\checkmark$ & & & & $\checkmark$ & $\checkmark$ & & \\
\hline $\begin{array}{l}\text { Biesinger } \\
\text { vd. }\end{array}$ & 2016 & $\checkmark$ & & & & $\checkmark$ & $\checkmark$ & & \\
\hline Gee vd. & 2016 & $\checkmark$ & & $\checkmark$ & & $\checkmark$ & $\checkmark$ & & \\
\hline Calvet vd. & 2016 & $\checkmark$ & & & & $\checkmark$ & $\checkmark$ & & \\
\hline Zhang vd. & 2016 & $\sqrt{ }$ & & $\checkmark$ & & $\checkmark$ & $\checkmark$ & & \\
\hline Liu vd. & 2016 & $\checkmark$ & & & & $\checkmark$ & $\checkmark$ & & \\
\hline Wang vd. & 2017 & $\checkmark$ & & & & $\checkmark$ & $\checkmark$ & & \\
\hline Qin vd. & 2017 & $\checkmark$ & & $\checkmark$ & & $\checkmark$ & $\checkmark$ & & \\
\hline Uslu vd. & 2017 & & $\checkmark$ & & & $\checkmark$ & $\checkmark$ & & \\
\hline $\begin{array}{l}\text { Saint- } \\
\text { Guillain vd. }\end{array}$ & 2017 & $\checkmark$ & & $\checkmark$ & & $\checkmark$ & $\checkmark$ & & \\
\hline Pasha vd. & 2017 & $\checkmark$ & & & & $\checkmark$ & $\checkmark$ & & \\
\hline $\begin{array}{l}\text { Bartazzi ve } \\
\text { Secomandi }\end{array}$ & 2018 & $\checkmark$ & & & $\checkmark$ & & & & $\checkmark$ \\
\hline $\begin{array}{l}\text { Louveaux } \\
\text { ve Salazar- } \\
\text { Gonzalez }\end{array}$ & 2018 & $\checkmark$ & & & & $\checkmark$ & $\checkmark$ & & \\
\hline Florio vd. & 2018 & $\checkmark$ & & & & $\checkmark$ & $\checkmark$ & & \\
\hline $\begin{array}{l}\text { Biesinger } \\
\text { vd. }\end{array}$ & 2018 & $\checkmark$ & & & & $\checkmark$ & $\checkmark$ & & \\
\hline $\begin{array}{l}\text { Subramanya } \\
\text { m vd. }\end{array}$ & 2018 & $\checkmark$ & & & & $\checkmark$ & $\checkmark$ & & \\
\hline Florio vd. & 2018 & $\checkmark$ & & & $\checkmark$ & & $\checkmark$ & & \\
\hline $\begin{array}{ll}\text { Zhu } & \text { ve } \\
\text { Sheu } & \\
\end{array}$ & 2018 & $\checkmark$ & & & $\checkmark$ & & & & $\checkmark$ \\
\hline Festa vd. & 2018 & $\checkmark$ & & & & $\checkmark$ & $\checkmark$ & & \\
\hline Hu vd. & 2018 & $\checkmark$ & & & & $\checkmark$ & $\checkmark$ & & \\
\hline $\begin{array}{ll}\text { Sun } & \text { ve } \\
\text { Wang } & \\
\end{array}$ & 2018 & $\checkmark$ & & $\checkmark$ & & $\checkmark$ & $\checkmark$ & & \\
\hline Dinh vd. & 2018 & $\checkmark$ & & & & $\checkmark$ & $\checkmark$ & & \\
\hline Calvet vd. & 2019 & & $\checkmark$ & & & $\checkmark$ & $\checkmark$ & & \\
\hline $\begin{array}{l}\text { Salavati- } \\
\text { Khoshghalb } \\
\text { vd. }\end{array}$ & 2019 & $\checkmark$ & & & & $\checkmark$ & $\checkmark$ & & \\
\hline $\begin{array}{l}\text { Salavati- } \\
\text { Khoshghalb } \\
\text { vd. }\end{array}$ & 2019 & $\sqrt{ }$ & & & & $\checkmark$ & $\checkmark$ & & \\
\hline
\end{tabular}


Tablo 5 (devamı): STARP Hakkında Yapılan Çalışmaların Değerlendirilmesi

\begin{tabular}{|l|l|l|l|l|l|l|l|l|l|}
\hline \multicolumn{1}{|c|}{ Yazar } & Y1lı & $\begin{array}{c}\text { Tek } \\
\text { Depolu }\end{array}$ & $\begin{array}{c}\text { Çok } \\
\text { Depolu }\end{array}$ & $\begin{array}{c}\text { Zaman } \\
\text { Pencereli }\end{array}$ & $\begin{array}{c}\text { Tek } \\
\text { Araçlı }\end{array}$ & $\begin{array}{c}\text { Çok } \\
\text { Araçlı }\end{array}$ & $\begin{array}{c}\text { Sadece } \\
\text { Dağıt }\end{array}$ & $\begin{array}{c}\text { Topla } \\
- \\
\text { Dağıt }\end{array}$ & $\begin{array}{c}\text { Zamanlı } \\
\text { Topla - } \\
\text { Dağıt }\end{array}$ \\
\hline $\begin{array}{l}\text { Salavati- } \\
\text { Khoshghalb } \\
\text { vd. }\end{array}$ & 2019 & $\checkmark$ & & & & $\checkmark$ & $\checkmark$ & & \\
\hline $\begin{array}{l}\text { Hernandez } \\
\text { vd. }\end{array}$ & 2019 & $\checkmark$ & & & & $\checkmark$ & $\checkmark$ & & \\
\hline Goel vd. & 2019 & $\checkmark$ & & $\checkmark$ & & $\checkmark$ & $\checkmark$ & & \\
\hline Arvianta vd. & 2019 & $\checkmark$ & & & & $\checkmark$ & $\checkmark$ & & \\
\hline
\end{tabular}

\section{Sonuç ve Değerlendirme}

ARP 1950'li y1llardan beri literatürde yer alan ve farklı kısıtlar altında da hala geliştirilmesi mümkün olan bir alandır. Artan rekabet şartları altında firmalar, müşterilere daha iyi hizmet verebilmek için tedarik ve lojistik yönetimine önem vermektedir. Firmalar uygun rotaları oluşturarak taşıma maliyetlerini minimuma çekmeyi amaçlamaktadır. Ancak gerçek hayat problemlerinde, tüm parametrelerin deterministik olmadığ1, değişken olduğu görülmektedir. SARP, problemdeki bir veya daha fazla parametrenin stokastik olduğu araç rotalama problemidir. Literatürde SARP konusunda yapılan çalışmalar incelendiğinde, en çok STARP hakkında çalışma yapıldığı dikkat çekmektedir. STARP, müşteri taleplerinin, araç müşterinin bulunduğu noktaya gidene kadar kesin olarak bilinmediği, ancak araç müşteri lokasyonuna vardığında talebin tam olarak öğrenildiği problemdir. Burada müşteri taleplerinin bir olasılık dağılımına sahip rassal değişkenlerden oluştuğu kabul edilmektedir.

$\mathrm{Bu}$ çalışmada STARP konusunda yapılan çalışmalar hakkında bir literatür taraması yapılmıştır. STARP konusunda yapılan çalışmalar, tek araç-çok araç, tek depolu-çok depolu, zaman pencereli, dağıt - topla-dağıt/ eş zamanlı topla dağıt durumlarını içerecek şekilde bir ayrıma tabi tutulmuş ve çalışmalar bu kısıtlar dikkate alınarak incelenmiştir. Ayrıca incelenen çalışmalarda problem için önerilen matematiksel model hakkında ve problemin çözümü için kullanılan yaklaşım hakkında bilgi verilmiştir. Daha sonra literatürde yapılan çalışmaların daha kolay analiz edilebilmesi için özet bir tablo oluşturularak, ortak kısıtları içeren çalışmalar belirlenebilmiştir. STARP konusunda yapılan çalışmalar 
incelendiğinde en çok çalışmanın Çok Araçlı STARP konusunda yapıldığ tespit edilmiştir.

STARP konusunda literatürde yapılan çalışmalar incelendiğinde, belirlenen kısıtlardan yalnız birini içeren problemlerin incelendiği, iki kısıtı birlikte inceleyen problemlerin ise sadece birkaç çalışmada ele alındığ 1 belirlenmiştir. Bu yüzden bundan sonraki çalışmalarda, stokastik talebin yanında, birden fazla deponun yer aldığı ve zaman penceresine dikkate alan Zaman Pencereli Çok Depolu STARP incelenebilir. Ayrıca, birden fazla deponun yer aldığı ve araçların toplama ve dağıtma taleplerini birlikte gerçekleştirdikleri Stokastik Talepli Çok Depolu Topla Dağıt ARP ile Stokastik Talepli Çok Depolu Eş Zamanlı Topla Dağıt ARP konularını içerecek çalışmalar da yapılabilir.

\section{Extended Summary}

Nowadays, travels, logistics and transportation issues are becoming more and more important for companies due to increasing competition. So, companies want to decrease the cost arised from travels and transportation. As a result, companies aim to minimize these costs by creating appropriate routes in their distribution networks.

Vehicle routing problem (VRP) is the problem of determining the distribution and/or collection routes of one or more vehicles serving customers who are situated in different locations, from one or more depots. VRP was studied first by Dantzig and Ramser in 1950s. Nowadays, researchers are working on VRP with different constraints to adopt changing market conditions and technology.

When we examine the studies in the literature, we see that researchers study the VRP which usually contains deterministic parameters. However, in real life problems, unpredictable parameter values are encountered. These parameters can have stochastic information. Stochastic vehicle routing problem (SVRP) arises when one or more parameters involved in the deterministic VRP are not known precisely. The aim for dealing with this problem is to minimize the expected routing cost. Variables that may include stochastic information can be customers, travel time, service time or customer demands, etc. These parameters consist of random variables with known probability distributions. SVRP types which are examined in literature: Vehicle Routing Problems with Stochastic 
Demand, Vehicle Routing Problem with Stochastic Service Times, Vehicle Routing Problem with Stochastic Customers, Vehicle Routing Problem witc Stochastic Travel Times, etc. When the studies in the literature are examined, it is seen that the researchers mostly focus on Vehicle Routing Problems with Stochastic Demand (VRPSD). VRPSD is a vehicle routing problem where customer demands are not known precisely until the vehicles reach the customer location. VRPSD is characterized by the fact that the demands from customers are random variables with a known probability distributions.

There are many studies about VRPSD in the literature. These studies on VRPSD can be divided into those that propose a mathematical model and offer a solution approach for solving the problem. There are two widely used approaches for modeling in the literature. One of them is chance-constrained stochastic programming approach, the other one is stochastic programming with recourse. The chance constraint approach is to make the deterministic of the variables with a certain probability distribution as much as possible in the problem where the stochastic variable contains constraints and the objective function. In stochastic programming with recourse, the route can have failure; however, once this route has failure, the decision maker determines which recourse action policy should be used to make route feasible.

SVRP is NP-hard problem, so this type of problems cannot be solved within reasonable time. So, researchers develop heuristics and metaheuristics solution methods for solving VRPSD within reasonable time. Especially in recent years, researchers have done a number of studies suggesting heuristic and metaheuristics solution approaches that will solve VRPSD in a reasonable time and find effective results.

In this article, studies on VRPSD in the literature have been examined. In this study, a classification was made by considering the constraints of the problem being single vehicle - multi vehicle, time windows, only delivery or pick up and delivery from single depot or multiple depot and the studies in the literature are discussed under these constraints. In addition, in the studies examined, the mathematical model proposed for the problem and the approach used to solve the problem are given. In order to analyze the studies in the literature more easily, a summary table was created and the studies containing common constraints could be determined. We also try to determine which problem the researchers mostly focused on. When the studies about VRPSD are 
examined, it is found that the most studies are carried out about Multi-Vehicle VRPSD. Furthermore, it has been seen that the studies conducted in recent years on VRPSD are more about approaches to solve the problem rather than the model proposed.

When the studies conducted in the literature on VRPSD are examined, it is found that problems involving only one of the identified constraints were examined mostly. In other words, only a few studies have two constraints which are examined together in the problem. Therefore, in the following studies, in addition to the stochastic demand, multi-depot VRPSD with time windows which includes more than one depot and takes into account time windows can be studied. Besides, researchers can also study multi-depot pick up and delivery/ simultaneously pick up and delivery VRPSD which have more than one depot and carry out the collection and distribution requests together.

\section{Kaynakça}

\section{Kitaplar}

Jaillet, P. ve Odoni, A. (1988). The Probabilistic Vehicle Routing Problem in Vehicle Routing: Methods and Studies, B. L. Golden and A. A. Assad (eds.), North-Holland, Amsterdam.

\section{Makaleler}

Ak, A., Erera, A.L., (2007). A Paired-Vehicle Recourse Strategy for the VehicleRouting Problem with Stochastic Demands, Transportation Science, 41, $222-237$.

Arvianto, A., Saptadi, S. Budiawan, W., Nartadhi, R.L. (2019). Vehicle routing problem model and simulation with probabilistic demand and sequential insertion, AIP Conference Proceedings.

Balaprakash, P. Birattari, M., Stützle, T., Dorigo, M. (2015), Estimation-based metaheuristics for the single vehicle routing problem with stochastic demands and customers, Computational Optimization and Applications, 61(2), 463-487. 
Bastian, C., Kan, R., (1992). The stochastic vehicle routing problem revisited, European Journal Of Operational Research, 56, 407-412.

Berhan, E. (2016), Stochastic vehicle routing problems with real simultaneous pickup and delivery services, Journal of Optimization in Industrial Engineering, 19, 1-7.

Bertazzi, L., Secomandi, N. (2018). Faster rollout search for the vehicle routing problem with stochastic demands and restocking, European Journal of Operational Research, 270(2018), 487-497.

Bertsimas, D. J., (1992). A vehicle routing problem with stochastic demand, Operations Research, 40 (3), 574-585.

Bertsimas, D. J., Chervi, P., Peterson, M., (1995). Computational approaches to stochastic vehicle routing problems, Transportation Science, 29 (4), 342352.

Bianchi, L., Birattari, M., Manfrin, M., Mastorolilli, M., Paquete, L., Rossi-Doria, O., Schiavinotto, T. (2004). Metaheuristics for the vehicle routing problem with stochastic demands, In International conference on parallel problem solving from nature 450-460, Springer Berlin Heidelberg,

Bianchi, L., Birattari, M., Manfrin, M., Mastrolilli, M., Paquete, L., Rossi-Doria, O., Schiavinotto, T., (2006). Hybrid Metaheuristics for the Vehicle Routing Problem with Stochastic Demand, Journal of Mathematical Modelling and Algorithms, 5, 91-110.

Biesinger, B., Hu., B., Raidl, G.R. (2015). A variable neighborhood search for the generalized vehicle routing problem with stochastic demands, Evolutionary Computation in Combinatorial Optimization, 48-60.

Biesinger, B., Hu., B., Raidl, G.R. (2016). An integer L-Shaped method for the generalized vehicle routing problem with stochastic demands, Electronic Notes in Discrete Mathematics, 52, 245-252.

Biesinger, B., Hu., B., Raidl, G.R. (2018). A genetic algorithm in combination with a solution archive for solving the generalized vehicle routing problem with stochastic demands, Transportation Science, 52(3), 497-.

Calvet, L., Juan, A.A., Schefers, N. (2015). Solving the Multi-Depot Vehicle Routing Problem considering Uncertainty and Risk Factors, Proceedings of the ICRA6/Risk International Conference, Barcelona, Spain. 
Calvet, L., Bernaus, A.P., Travessat-Baro, O., Juan, A.A. (2016). A Simheuristic for the heterogeneous site-dependent asymetric VRP with stochastic demands, Advances in Artificial Intelligence, 408-417.

Calvet, L.,Wang, D., Juan, A., Bove, L. (2019) Solving the multidepot vehicle routing problem with limited depot capacity and stochastic demands, International Transactions in Operational Research, 26(2019), 459-484.

Chan, Y. , Carter, W. B. , Burnes, M. D. (2001). A multiple-depot, multiplevehicle, location-routing problem with stochastically processed demands, Computers \& Operations Research, 28(8), 803-826.

Chang, M.S. (2005). A vehicle routing problem with time windows and stochastic demands, Journal of the Chienese Institute of Engineering, 28(5),783-794.

Desticioğlu, B. ve Özyörük, B. (2019). Dinamik ARP, Çok Depolu ARP ve Eş Zamanlı Topla Dağıt ARP İçin Literatür Taraması, MAS International Conference on Mathematics-Engineering and Natural\&Medical SciencesIII, 345-363.

Dimitrakos, T.D. ve Kyriakidis, E.G. (2015). A single vehicle routing problem with pickups and deliveries continous random demands and predefined customer order, European Journal of Operational Research, 244(3), 990993.

Dinh, T., Fukasawa, R., Luadtka, J. (2018). Exact algorithms for the chanceconstrained vehicle routing problem, Mathematical Programming, 172(12), 105-138.

Dror, M., Laporte, G., Trudeau, P., (1989).Vehicle routing with stochastic demands; Properties and solution frameworks, Transportation Science, 23 (3), 166-176.

Dror, M., Trudeau, P., (1986). Stochastic vehicle routing with modified savings algorithm, European Journal of Operational Research, 23, 228-235.

Dror, M., (1993). Modeling Vehicle Routing with Uncertain Demands as a Stochastic Program: Properties of the Corresponding Solution, European Journal of Operational Research, 64, 432-441.

Dror, M., Laporte, G., Louveaux, F.V. (1993). Vehicle routing with stochastic demands and restricted failures, ZOR Zeitschrift für Operations Research Methods and Models of Operation Research 37(3), 273-283. 
Dror, M. (2016). Vehicle routing with stochastic demands: Models \& computational methods, International Series in Operations Research and Management Science, 46, 425-449.

Erera, A.L., Savelsbergh, M., Uyar, E. (2009). Fixed routes with backup vehicles for stochastic vehicle routing problems with time constraints, Networks, 54(4), 270-283.

Erera, A.L., Morales, J.C., Savelsbergh, M. (2010). The vehicle routing problem with stochastic demand and duration constraints, Transportation Science, 44(4), 474-492.

Festa, P., Pastore, T., Ferore, D., Juan, A.A., Bayliss, C. (2018). Integrating Biased-randomized GRASP with Monte Carlo simulation for solving the vehicle routing problem with stochastic demands, 2018 Winter Simulation Conference, 2989-3000.

Gauvin, C., Desaulniers, G., Gendreau, M. (2014). A branch-cut-and-price algorithm for the vehicle routing problem with stochastic demands, Computers \& Operations Research, 50, 141-153.

Gee, S.B., Arokiasami, W.A., Jiang, J., Tan, K.C. (2016), Decomposition-based multi-objective evolutionary algortihm for vehicle routing problem with stochastic demands, Soft Computing, 20(9), 3443-3453.

Gendreau, M., Laporte, G., Seguin, R. (1995). An exact algorithm for the vehicle routing problem with stochastic demands and customers, Transportation Science, 29(2), 143-155.

Gendreau, M., Laporte, G., Guo, B. (1996). Stochastic vehicle routing: Invited review, European Journal of Operational Research, 88, 3-12.

Ghilas, V., Demir, E. ve Woensel, T.V. (2016). A scenerai-based planning for the pickup and delivery problem with time windows, scheduled lines and stochastic demands, Transportation Research Part B: Methodological, 91, 34-51.

Goel, R., Maini, R., Bansal, S. (2019), Vehicle routing problem with time windows having stochastic customer demands and stochastic service times: Modeling and solution, Journal of Computational Science, 34, 1-10.

Goodson, J.C., Ohlmann, J.W., Thomas, B.W. (2012). Cyclic-order neighborhoods with application to the vehicle routing problem with stochastic demand, European Journal of Operational Research,217(2), 312-323. 
Goodson, J.C. (2015). A priori policy evaluation and cyclic-order-based simulated annealing for the multicompartment vehicle routing problem with stochastic demands, European Journal of Operational Research, 241(2), 361-369.

Goodson, J.C., Thomas, B.W., Ohlmann, J.W. (2015). Restocking-based rollout policies for the vehicle routing problem with stockhastic demand and duration limits, Transportation Science, 50(2), 363-370.

Gounaris, C.E., Wiesemann, W., Floudas, C.A. (2013). The robust capacitated vehicle routing problem under demand uncertainty, Operations Research, 61(3), 677-693.

Gutierrez, A. Dieulle, L., Labadie, N. ve Velasco, N. (2018). A hybrid metaheuristic algorithm for the vehicle routing problem with stockhastic demands, Computers \& Operations Research, 99, 135-147.

Haugland, D., Ho, S.C., Laporte, G. (2007). Designing delivery districts for the vehicle routing problem with stochastic demands, European Journal of Operational Research, 180(3), 997-1010.

Hernandez, F., Gendreau, M., Jabali, O. ve Rei, W. (2019). A local branching metaheuristic for the multi-vehicle routing problem with stochastic demands, Journal of Heuristics, 25(2),215-245.

Hjorring, C., Holt, J. (1999). New optimality cuts for a single-vehicle stochastic routing problem, Annals of Operations Research, 86, 569-584.

Hou, L., Hou, Z. (2013). A novel discrete differential evolution algorithm, Telkomnika, 11(4), 1883-1888.

Hou L., Zhou, H., (2010). Stochastic vehicle routing problem with uncertain demand and travel time and simultaneous pickups and delivery, Third International Joint Conference on Computational science and Optimization, 32-35.

Hou, L., Zhou, H., Zhao, J., (2010). A novel discrete differential evolution algorithm for stochastic VRPSPD, Journal of Computational Information Systems, 6(8), 2483-2491.

Hu, C., Lu, J., Liu, X. Ve Zhang, G. (2018). Robust vehicle routing problem with hard time windows under demand and travel time uncertainty, Computational Optimization and Applications, 61(2), 463-487. 
Ismail, Z. Ve Irhamah, I. (2008). Solving the vehicle routing problem with stochastic demands via hybrid genetic algorithm- tabu search, Journal of Mathematics and Statistics, 4(3), 161-167.

Jabali, O., Rei, W., Gendreau, M., Laporte, G. (2014). Partial-route inequalities for the multi-vehicle routing problem with stochastic demands, Discrete Applied Mathematics, 177, 121-136.

Juan, A., Faulin, J., Grasman, S., Riera , D., Marull, J., Mendez, C. (2011) Using safety stocks and simulation tosolve the vehicle routing problem with stochastic demands, Transportation Research Part C:EmergencyTechnology, 19(5), 751-765, Freight Transportation and Logistics.

Juan, A., Faulin, J., Jorba, J., Cacares, J., Marques, J.M. (2013) Using parallel \& distributed computing solving real time vehicle routing problems with stochastic demands, Annals of Operations Research, 207(1), 43-65.

Kyriakidis, E.G. ve Dimitrakos, T.D. (2015). Single vehicle routing problem with a predefined customer sequence, stochastic demands and partial satisfaction of demands, Operations Research Proceedings, 157-164.

Laporte, G., Louveaux, F., Mercure, H. (1989). Models and exact solutions for a class of stochastic location-routing problems, European Journal of Operational Research, 39(1), 71-78.

Laporte, G., Louveaux, F., (1990). Formulations and Bounds for Stochastic Vehicle Routing Problem with Uncertain Supplies in Economic DecisionMaking: Games, Econometrics, and Optimization, J. J. Gabzewicz, J. F. Richard, and L. A. Wolsey (eds.), North-Holland, Amsterdam.

Laporte, G., Louveaux, F.V., Hamme, L.V. (2002). An integer L-shaped algorithm for the capacitated vehicle routing problem with stochastic demands, Operational Research, 50(3), 415-423.

Lee, C., Lee, K., Park, S. (2012). Robust vehicle routing problem with deadlines and travel time/demand uncertainty, Journal of Operational Research Society, 63(9), 1294-1306.

Lei, H. , Laporte, G. ,Guo, B. (2011). The capacitated vehicle routing problem with stochastic demands and time windows, Computers \& Operations Research, 38(12), 1775-1783. 
Liu, C., Kou, G., Huang, F. (2016). Vehicle coordinated strategy for vehicle routing problem with fuzzy demands, Mathematical Problems in Engineering, 2016, 1-10.

Louveaux, F.V. ve Salazar-Gonzalez, J.J. (2018). Exact approach for the vehicle routing problem with stockhastic demands and preventive returns, Transportation Science, 52(6), 1297-

Luo, Z., Qin, H., Zhang, D. Ve Lim, A. (2016). New exact algorthm and solution properties for the vehicle routing problem with stochastic demands and weight-related cost, Transportation Research Part E: Logistics and Transportation Review, 85, 69-89.

Marinaki, M. ve Marinakis, Y. (2016). A glowworm swarm optimization algorithm for the vehicle routing problem with stockhastic demands, Expert Systems with Applications, 46, 145-163.

Marinakis, Y., Iordanidou, G.R., Marinaki, M. (2013). Particle swarm optimization for the vehicle routing problem with stochastic demands, Applied Soft Computing, 13(4), 1693-1704.

Marinakis, Y., Marinaki, M. ve Spanou, P. (2015). A memetic differantial evolution algorthm for the vehicle routing problem with stochastic demands, Adaptation and Hybridization in Computational Intelligence, 18, 185-204.

Mendoza, J.E., Castanier, B., Gue'ret, C., Medaglia, A.L., Velasco, N. (2010). A memetic algorithm for the multi compartment vehicle routing problem with stochastic demands. Computers \& Operations Research, 37(11), 1886-1898.

Mendoza, J.E., Villegas, J.G. (2013). A multi-space sampling heuristic for the vehicle routing problem with stochastic demands, Optimization Letters, 7(7), 1503-1516.

Mendoza, J.E., Rousseau, L.M. ve Villegas, J.G. (2016). A hybrid metaheuristics for the vehicle routing problem with stochastic demand and duration constraints, Journal of Heuristics, 22(4), 539-566.

Minis, I., Tatarakis, A. (2011). Stochastic single vehicle routing with pick up and a predefined customer sequence, European Journal of Operational Research, 213, 37-51. 
Moghaddam, B.F. , Ruiz, R., Sadjadi, S.J. (2012). Vehicle routing problem with uncertain demands: An advanced particle swarm algorithm, Computers \& Industrial Engineering, 62(1), 306-317.

Novoa, C., Storer, R. (2009). An approximate dynamic programming approach for the vehicle routing problem with stochastic demands, European Journal of Operational Research, 196(2), 509-515.

Ong, H.L., Ang, B.W., Goh, T.N., Deny, C.C.(1997). A vehicle routing and scheduling problem with time windows and stochastic demand constraints, Asia-Pacific Journal of Operational Research, 14, 1-17.

Oyola, J., Arntzen, H., Woodruff, D.L., (2018) The stochastic vehicle routing problem a literature review, part I: models, EURO J Trasp Logist, 7, 193221.

Pasha, U., Hoff, A., Hvattum, L.M. (2017). The multi-period fleet size and mix vehicle routing problem with stochastic demands, Computational Methods and Models for Transport, 121-146.

Qin, J., Ye, Y., Cheng, B. Zhao, X. Ve Ni, L. (2017). The emergency vehicle routing problem with uncertain demand under sustainability environments, Sustainability, 9(2), 288-

Rei, W., Gendreau, M., Soriano, P. (2010). A hybrid monte carlo local branching algorithm for the single vehicle routing problem with stochastic demands, Transportation Science, 44(1), 136-146.

Ritzinger, U., Punchinger, J., Hartl, R.F. (2016). A survey on dynamic and stochastic vehicle routing problems, International Journal of Production Research, 54(1), 215-231.

Saint-Guillian, M., Solnon, C., Deville, Y. (2017)., The static and stochastic VRP with time windows and both random customers and reveal times, Applications of Evolutionary Computation, 110-127.

Salavati-Khosghalb, M., Gendreau, M., Jabali, O., ve Rei, W. (2019a). A rulebased recourse for the vehicle routing problem with stockhastic demands, Transportation Science

Salavati-Khosghalb, M., Gendreau, M., Jabali, O., ve Rei, W. (2019b). An exact algorithm to solve the vehicle routing problem with stockhastic demands under an optimal restocking policy, European Journal of Operational Research, 273(1), 175-189. 
Salavati-Khosghalb, M., Gendreau, M., Jabali, O., ve Rei, W. (2019c). A hybrid recourse policy for the vehicle routing problem with stockhastic demands, Euro Journal on Transportation and Logistics, 8(3), 269-298.

Sarasola, B. Doerner, K.F., Schmid, V., Alba, E. (2016). Variable neighborhood search for the stochastic and dynamic vehicle routing problem, Annals $o$ Operations Search,236(2), 425-461.

Secomandi, N., (2000). Comparing neuro-dynamic programming algorithms for the vehicle routing problem with stochastic demands, Computers and Operations Research, 27 (5), 1171-1200.

Secomandi, N., (2001). A rollout policy for the vehicle routing problem with stochastic demands, Operations Research, 49 (5), 796-802.

Secomandi, N., Margot, F. (2009). Reoptimization approaches for the vehiclerouting problem with stochastic demands, Operational Research, 57(1), 214-230.

Soonpracha, K., Mungwattana, A., Manisri, T. (2015). A re-constructed metaheuristic algorithm for robust fleet size and mix the vehicle routing problem with time windows under uncertain demands, Evolutionary Systems, 2, 347-361.

Stewart, W., R., Golden, B., L., (1983). Stochastic vehicle routing : A comprehensive approach, European Journal Of Operational Research, 14, 371-385.

Sungur, I, Ordo'nez, F., Dessouky, M. (2008). A robust optimization approach for the capacitated vehicle routing problem with demand uncertainty, IIE Transactions, 40, 509-523.

Sun, L. ve Wang, B. (2018). A goal-robust-optimization approach for solving open vehicle routing problem with demand uncertainty, Wireless Personal Communications, 103(1), 1059-1075.

Tan, K. C., Cheong, C. Y., Goh, C. K. (2007). Solving multiobjective vehicle routing problem with stochastic demand via evolutionary computation, European Journal of Operational Research, 177(2), 813-839.

Tatarakis, A. ve Minis, I. (2009). Stochastic single vehicle routing with a predefined customer sequence and multiple depot returns, European Journal of Operational Research, 197(2), 557-571. 
Teng, S., Ong, H.L., Huang, H.C., (2003). A comparative study of metaheurıstics for vehicle routıng problem with stochastic demands, Asia-Pacific Journal of Operational Research, 20, 103-119.

Teodorovi'c, D., Pavkovi'c, G., (1992).A simulated annealing technique approach to the vehicle routing problem in the case of stochastic demand, Transportation Planning and Technology, 16, 261-273.

Tillman, F. A. (1969).The multiple terminal delivery problem with probabilistic demands. Transportation Science, 3(3), 192-204.

Ulmer, M.W., Mattfeld, D.C., Hennig, M. Ve Goodson, J.C. (2015). A rollout algorithm for vehicle routing with stockhastic customer requests, Logistic Management, 217-227.

Uslu, A., Çetinkaya, C., İşleyen, S.K., (2017). Vehicle routing problem in postdisaster humanitarian relief logistics: A case study in Ankara, Sigma Journal of Engineering and Natural Science, 35(3), 481-499.

Wang, C., Qiu, Y. (2011). Vehicle routing problem with stochastic demands and simultaneous delivery and pickup based on the cross-entropy method, Advances in Automation and Robotics, 2, 55-60.

Wang, K., Lan, S. ve Zhao, Y. (2017). A genetic-algorithm-based approach to the two echelon capacited vehicle routing problem with stochastic demands in logistics service, Journal of the Operational Research Society, 68(11), 1409-1421.

Xaingguo, M., Manying, W. (2015). Optimization model of the vehicle routing of cold chain logistics based on stochastic demands, Journal of Applied Science and Engineering Innovation, 2(9), 356-362.

Yang, W., Mathur, K., Ballou, R. H., (2000). Stochastic vehicle routing problem with restocking, Transportation Science, 34 (1), 99-112.

Zhang, J., Lam, W.H.K., Chen, B.W. (2016). On-time delivery probabilistic models for the vehicle routing problem with stochastic demands and time windows, European Journal of Operational Research, 249(1), 144-154.

Zhang, C., Delleart, N.P., Zhao, L., Van Woenseş, T., Sever, D. (2013), Single vehicle routing problem with stochastic demands: Approximate dynamic programming, Eindhoven University of Technology, 425, 1-29.

Zhu, L., Rousseau, L-M., Rei, W., Li, B. (2014). Paired cooperative reoptimization strategy for the vehicle routing problem with stochastic demands. Computers \& Operations Research, 50, 1-13. 
Zhu, L. ve Sheu, J.B. (2018). Failure-specific cooperative recourse strategy for simultaneous pick up and delivery problem with stochastic demands, European Journal of Operational Research, 271(3), 896-912.

Zuhori, S.T., Peya, Z.J., Mahmud, F. (2013). A novel three-phase approachfor solving multi-depot vehicle routing problem with stochastic demand, Algorithms Research, 1(4), 15-19.

\section{Tezler}

Gültepe, A. (2011). "Stokastik eş zamanlı topla-dağıt araç rotalama problemi için melez yaklaşım: Diferansiyel evrim algoritması", Yüksek Lisans Tezi, Başkent Üniversitesi Fen Bilimleri Enstitüsü, Ankara.

İşleyen, S.K. (2008). "Lojistik yönetim sistemlerinde stokastik talepli araç rotalama problemi”, Yüksek Lisans Tezi, Gazi Üniversitesi Fen Bilimleri Enstitüsü, Ankara.

Kızıloğlu, K. (2017). "Stokastik talepli çok depolu araç rotalama problemi için sezgisel bir çözüm yaklaşımı”, Yüksek Lisans Tezi, Gazi Üniversitesi Fen Bilimleri Enstitüsü, Ankara.

Uslu, A. (2016). "Afet Sonrası İnsani Yardım Lojistiğinde Stokastik Talepli Çok Depolu Araç Rotalama Problemi: Ankara İli Örneği”, Yüksek Lisans Tezi, Gazi Üniversitesi Fen Bilimleri Enstitüsü, Ankara.

Yang, W.H., (1996). Stochastic Vehicle Routing with Optimal Restocking, PhD thesis, Case Western Reserve University, Cleveland, OH, U.S.A. 16-18.

\section{İnternet Kaynakları}

Christiansen, C.H., Eglese, R.W., Letchford, A.N., Lysgaard, J. (2016). A Branch-and-Cut-and-Price algorithm for the Multi-Depot Capacitated Vehicle Routing Problem with Stochastic Demands, https://www.researchgate.net/publication/229169058_A_branch-and-cutand-price_algorithm_for_the_multi-depot_heterogeneous_vehicle_routing _ problem_with_time_windows, Son erişim tarihi:26.08.2019.

Florio, A., Hartl, R., Minner, S. (2018), New exact algorithm and solution properties fort he vehicle routing problem with stachastic demands, https://arxiv.org/abs/1806.08549, Son Erişim Tarihi: 28.08.2019. 
Florio, A., Hartl, R., Minner, S. (2018), Optimal a priori tour and restocking policy for the single vehicle routing problem with stochastic demands, https://www.sciencedirect.com/science/article/abs/pii/S0377221718309135 Son Erişim Tarihi: 30.08.2019.

Subramanyam, A., Repoussis, P.P., Gounaris, C.E. (2018). Robust optimization of broad class of heterogeneous vehicle routing problems under demand uncertainty, 1-54, https://arxiv.org/abs/1810.04348, Son Erişim Tarihi: 08.09.2019. 